\title{
Rapid light curves (RLC) or non-sequential steady-state light curves (N-SSLC): which fluorescence-based light response curve methodology robustly characterizes phytoplankton photosynthetic activity and acclimation status?
}

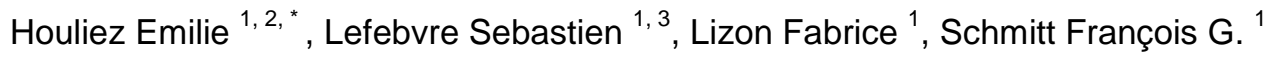

${ }^{1}$ Université de Lille 1, CNRSUniversité du Littoral Côte d'Opale, UMR 8187, LOG, Laboratoire

d'Océanologie et de GéosciencesWimereux,France

${ }^{2}$ Institut du Littoral et de l'Environnement (ILE)Université de La Rochelle, CNRS, UMR 6250 LIENSsLa

Rochelle Cedex,France

${ }^{3}$ Laboratoire Ressources HalieutiquesIFREMERBoulogne-sur-Mer,France

* Corresponding author : Emilie Houliez, email address : emilie.houliez@outlook.fr

\begin{abstract}
:
This study is the first in situ work comparing rapid light curves (RLC) and non-sequential steady-state light curves (N-SSLC) in their efficiency to characterize phytoplankton photosynthetic activity and acclimation status. Measurements were carried out at two time scales (daily and annual) using the Pulse Amplitude Modulated fluorometry on samples taken in the coastal waters of a macrotidal ecosystem (the Strait of Dover, eastern English Channel). RLC and N-SSLC were compared under a wide range of environmental conditions and phytoplankton composition in order to define the best methodology to accurately capture short and long-term adjustments in the functioning of the photosynthetic apparatus. The relationships between the photosynthetic parameters extracted from RLC and N-SSLC were also studied to evaluate the possibility to use RLC to predict N-SSLC photosynthetic parameters and thus obtaining the acclimation status at steady state. At daily scale, the maximum electron transport rate and light saturation coefficient resulting from RLC (respectively, ETRm_RLC and Ek_RLC) were found to follow more closely short-term environmental light variations than ETRm and Ek resulting from N-SSLC (ETRm_N-SSLC and Ek_N-SSLC) did. RLC were thus able to detect rapid changes in photosynthetic activity that would have been overlooked with N-SSLC measurements. At annual scale, few differences were found between RLC and N-SSLC. Variations of ETRm and $\alpha$ derived from RLC and N-SSLC were very similar but absolute values were lower for RLC measurements. Because, at daily scale, RLC better capture the short-term changes in photosynthetic activity than N-SSLC do, using RLC to predict N-SSLC photosynthetic parameters and getting information about steady-state acclimation status is not possible at this time scale. However, this can be done at seasonal scale.
\end{abstract}


Within their natural environment, phytoplankton species are exposed to highly variable conditions including strong fluctuations in the degree of water mixing, light intensity, nutrients availability and temperature (MacIntyre et al. 2000). These never-ending changes, operating at different scales in space and time, can be considerably stressful for phytoplankton and this influences their growth rate, photosynthetic activity and survival (Geider et al. 1998). In order to maintain optimal growth and photosynthetic performances under such variable conditions, phytoplankton have developed different mechanisms including photoacclimation which allow them to avoid damaging energy imbalance within the photosynthetic apparatus (Brunet et al. 2011). Understanding these processes of acclimation and their controlling factors is a critical issue in phytoplankton ecology and this requires accurate measurement methodology.

The so-called photosynthesis-light response (PE) curves, in which photosynthetic rates are plotted against a range of irradiance intensities, are one of the most widely used methods to characterize phytoplankton photosynthetic performances and acclimation status (Henley 1993; MacIntyre and Kana 2002; Sakshaug et al. 1997). PE curves were presented in literature as early as 1930 's (e.g. Baly 1935) but their measurement became popular with the development of the traditional photosynthesis measurement techniques based on $\mathrm{C}$ isotopeincorporation (Hama et al. 1983; Steemann Nielsen 1952) or oxygen evolution (Gaarder and Gran 1927; Montford 1969). Using these techniques, a PE curve is obtained either by a 
sequential measurement of oxygen exchange rates on a single sample exposed to several steps of different irradiances or by simultaneous measurements of ${ }^{14} \mathrm{C}$ incorporation on several subsamples (drawn from a single phytoplankton sample) and each exposed to constant irradiances of different intensity (MacIntyre and Kana 2002). Even though these traditional techniques are still widely used in phytoplankton ecology, they are associated with several methodological drawbacks reducing their practicality such as the requirement of incubation time that limits the resolution at which measurements can be made, the low sensitivity and concentration steps of oximetry based-methods, and the so-called bottle effect (Lefebvre et al. 2007).

Consequently, these last few years, there was a great deal of interest in alternative optical techniques based on active chlorophyll fluorescence because they enable to measure photosynthesis at a higher spatiotemporal resolution and free of the constraints associated with the traditional techniques (Kromkamp and Forster 2003; Suggett et al. 2010). Fluorescence-based techniques, including the Pulse Amplitude Modulated (PAM) (Schreiber 2004) and Fast Repetition Rate Fluorometry (FRRF) (Kolber et al. 1998), measure the rate at which electrons flow from water through photosystems II to NADPH and other electron acceptors (Lawrenz et al. 2013). A PE curve built using these techniques measures thus the electron transport rate (ETR) under a range of irradiance levels and is called ETR vs. E curve. The growing interest for these techniques introduced at the same time new methodologies to construct PE curves and raised new questions about the best way to measure phytoplankton photosynthesis and acclimation status.

Steady-state light curves (SSLC) were the first fluorescence-based methodology employed because they are comparable to the traditional PE curves based on $\mathrm{C}$ isotopeincorporation or oxygen evolution. SSLC measure the photosynthesis rate at steady-state i.e. with light steps long enough to allow the stabilisation of photosynthetic processes under each irradiance level. As a consequence, the transient effects of recent light history, defining the short-term acclimation status before the start of SSLC, are attenuated (even eliminated) during their construction (Cruz and Serôdio 2008). SSLC are thus used to study the long-term acclimation status (hours to days) and the potential photosynthetic performances of autotrophic organisms (Cruz and Serôdio 2008; Perkins et al. 2010; Serôdio et al. 2006). SSLC can be constructed following two methodologies. The non sequential steady-state light curves (N-SSLC) are built by applying each light step on different subsamples (Herlory et al. 2007; Perkins et al. 2006). Measurements are independent from each other and the 
photosynthetic activity measured at each light step only depends on the irradiance to which the sample is exposed at the moment of measurement. By opposition, the sequential steadystate light curves (S-SSLC) are built by applying all the light steps on the same sample. Measurements lost their independency and the photosynthetic activity measured at each light step depends not only on the irradiance to which the sample is exposed at the moment of measurement but also on the irradiance experienced (and accumulated) during the previous step(s) (recent light history) (Frankenbach and Serôdio 2017; Herlory et al. 2007). Both protocols are time-consuming as they require several minutes to a few hours to be completed. This is a constraint for field studies because: 1) the time required to complete the protocol makes replication impossible and 2) investigation of temporal and spatial variations in photosynthetic activity may be jeopardized by the time spent by users to obtain a single set of measurements (Perkins et al. 2010). This is particularly true in highly variable systems for which a high spatio-temporal resolution is required to completely capture changes in photosynthetic activity in response to rapidly fluctuating environmental conditions. Another limitation of these methods is that sample's acclimation status is strongly modified during the curve building while the goal of SSLC measurements is normally to characterize the acclimation status developed in situ.

To limit these acclimation processes occurring during the curve building, another methodology called Rapid Light Curves (RLC) was introduced (Schreiber et al. 1997; White and Critchley 1999). RLC are built with short light steps ( $\leq 30 \mathrm{~s})$ and preserve the acclimation state attained immediately prior to the start of the curve measurement. They allow thus to describe the effective photosynthetic capacities and short-term acclimation status (Herlory et al. 2007; Perkins et al. 2006; Serôdio et al. 2005b; Serôdio et al. 2006). Because of the short duration of their light steps, RLC can be completed within 80-240 s (depending on the number and duration of light steps) which shortens drastically the time required for their measurement and represents a considerable operational advantage during field works (Cruz and Serôdio 2008; Perkins et al. 2010).

RLC were used to characterize the effective photosynthetic activity and short-term acclimation status of different autotrophic organisms including macroalgae, ice microalgae, corals and seagrasses (Serôdio et al. 2005b and references therein) and were widely applied on microphytobenthic assemblages (e.g. Cruz and Serôdio 2008; Herlory et al. 2007; Lefebvre et al. 2011; Perkins et al. 2006; Serôdio et al. 2008; Serôdio et al. 2005b; Serôdio et al. 2006). Several methodological studies were even conducted to examine the usefulness of RLC and 
improve the measurement protocol to assess microphytobenthos photosynthetic activity (Lefebvre et al. 2011 and references therein).

However, despite the potential advantages offered by this methodology, RLC remain seldom applied for studying phytoplankton photosynthetic activity. This is probably because RLC raise some questions about the physiological interpretation of the resulting photosynthetic parameters, particularly in comparison with the other methodologies (Herlory et al. 2007). Indeed even though RLC are less intruvise than SSLC, this does not mean they are completely free of any acclimation processes occuring during the curve building. It was shown that light steps duration and order (i.e. increasing or decreasing light steps) influence the photosynthetic parameters extracted from RLC and involve physiological processes that can be different from the ones operating during the SSLC building (Herlory et al. 2007; Lefebvre et al. 2011; Perkins et al. 2006). To our knowledge, no previous study compared phytoplankton photosynthetic parameters extracted from RLC and S-SSLC or N-SSLC. Consequently, for the users of fluorescence-based techniques who wish to study phytoplankton photosynthesis it is still difficult to know which methodology they should employ to accurately characterize phytoplankton photosynthetic performances and acclimation status. Ideally the protocol employed should not take too much time to be completed, should allow for replication and should estimate properly the short- and long-term acclimation status in one measurement.

This study aimed: 1) to compare RLC and N-SSLC in their efficiency to characterize in situ dynamics of phytoplankton photosynthetic activity at different time scales and 2) to study the relationships between the photosynthetic parameters extracted from RLC and NSSLC measured under different environmental conditions in order to define the possibility to use RLC to predict N-SSLC parameters and thus characterize the long-term acclimation status. Because RLC use light steps too short to completely alter the acclimation status formed just before the curve measurement, in opposition to N-SSLC, we hypothesized that RLC can detect rapid changes in photosynthetic activity that would have been passed unnoticed if $\mathrm{N}$ SSLC were measured. We also hypothesized that relationships between the photosynthetic parameters extracted from RLC and N-SSLC can be different according to the time scale considered.

Samplings were carried out in the coastal waters of Wimereux at two time scales (daily and annual). Photosynthetic activity was measured on natural phytoplankton 
communities using the PAM fluorometry. ETR vs. E curves were constructed using RLC and $\mathrm{N}-\mathrm{SSLC}$ in order to compare the resulting photosynthetic parameters.

\section{Materials and methods}

Study area and sampling

The study was completed in the coastal waters of Wimereux $\left(50^{\circ} 45^{\prime} 57.42^{\prime}{ }^{\prime} \mathrm{N}\right.$, 1³5'55.17'E, depth range: 1-4 m) situated in the English Channel; a well-mixed macrotidal ecosystem (Fig. 1). Further information on this study area are available in Houliez et al. (2013b). Samples were collected in surface waters using a bucket from the foreshore next to our institute using two different protocols according to the time scale considered. At daily scale, samples were taken every $1.45 \mathrm{~h}$. from sunrise to sunset in winter (January $28^{\text {th }} 2010$ ), spring (March $18^{\text {th }}$ and $26^{\text {th }} 2010$ ) and summer (July $23^{\text {th }}$ and $29^{\text {th }} 2010$ ). At annual scale, samples were collected once per week from February 2009 to August 2010 at high and low tide.
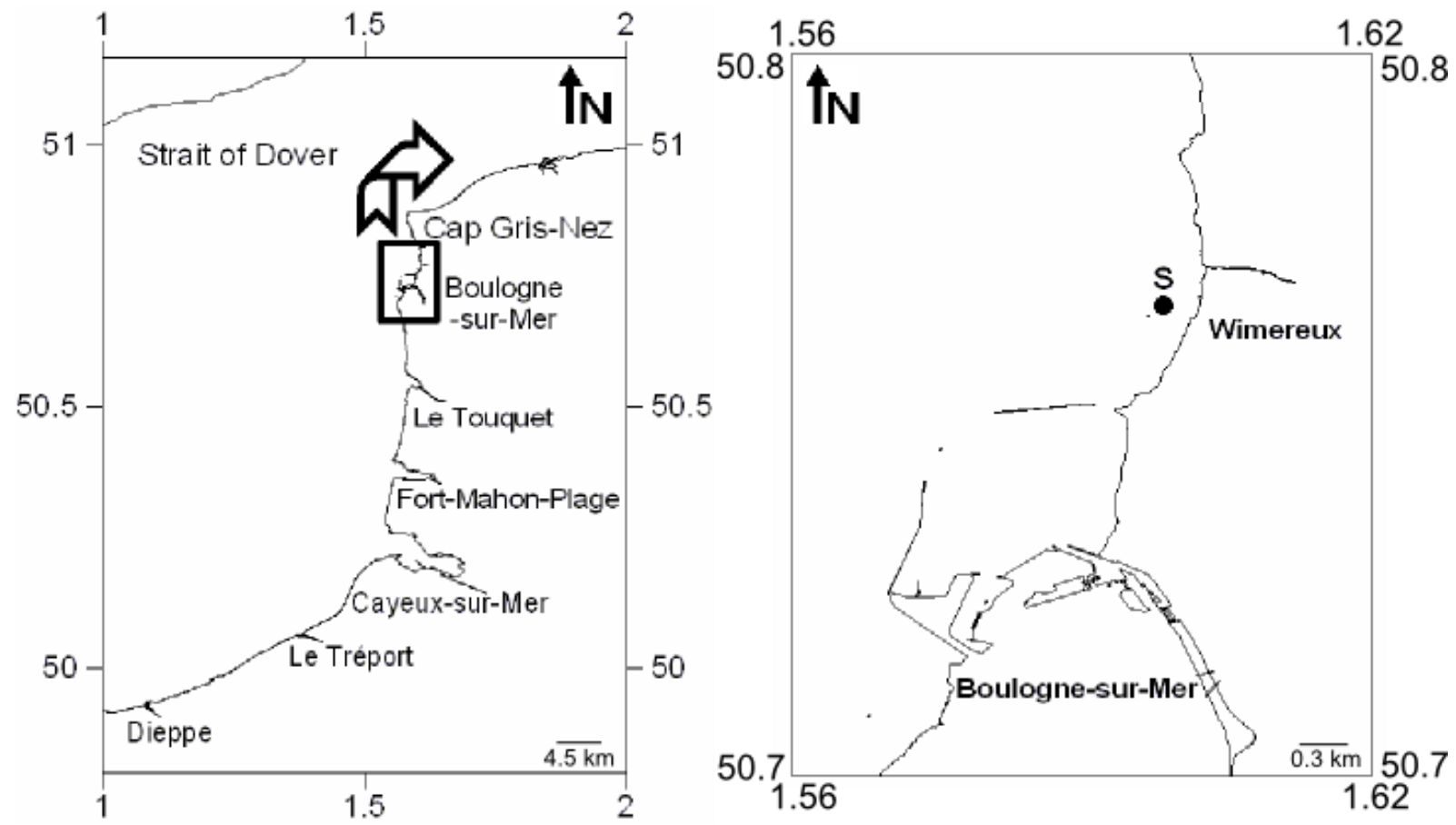

Fig. 1 Map of the Strait of Dover with enlarged area representing the location of sampling station (S). Coordinates are in decimal degrees 


\section{Environmental parameters and phytoplankton community structure}

Seawater temperature and salinity were obtained by using a conductivity meter (Cond. 315i, WTW, Weilheim, Germany). Nutrients $\left(\mathrm{NO}_{3}{ }^{-}, \mathrm{NO}_{2}{ }^{-}, \mathrm{Si}(\mathrm{OH})_{4}, \mathrm{PO}_{4}{ }^{3-}\right)$ were measured with an Alliance Integral Futura Autoanalyser II according to the method of Aminot and Kérouel (2007). Incident photosynthetically active radiation (PAR in $\mu \mathrm{mol}$ quanta $\mathrm{m}^{-2} \mathrm{~s}^{-1}$ ) was measured continuously ( 1 measurement per minute) with a $4 \pi$ spherical quantum sensor (ultra-miniature MDS-MkV/L, JFE Alec Electronics co. LTD., Kobe, Japan).

The composition of phytoplankton community was investigated using a submersible spectral fluorometer (the FluoroProbe, bbe-Moldaenke, Kiel, Germany) after the recalibration of its reference fingerprints (further details are provided in Houliez et al. 2012). This recalibration allows the discrimination of four spectral algal groups in mixed populations: brown algae (diatoms + dinoflagellates), cyanobacteria (cyanobacteria with phycocyanin), the Haptophyte Phaeocystis globosa and "Cryptophyta" (Cryptophyta, Rhodophyta, cyanobacteria with phycoerythrin). Measurements on phytoplankton samples were made using the $25 \mathrm{~mL}$ cuvette of the FluoroProbe.

\section{Photosynthetic activity}

Photosynthetic activity was measured by Pulse Amplitude Modulated (PAM) fluorometry using a Phyto-PAM fluorometer (Heinz Walz GmbH, Effeltrich, Germany). For a detailed description of the Phyto-PAM, see Kolbowski and Schreiber (1995) and Schreiber (1998). Measurements were made on suspension using the quartz cuvette of the Phyto-PAM with samples of $2.5 \mathrm{~mL}$. Before the measurements of ETR vs. E curves, samples were darkacclimated during 15 minutes at sampling temperature.

RLC were constructed by exposing samples for $10 \mathrm{~s}$ to 21 sequential increasing light steps $(14,41,53,80,94,145,175,206,236,295,323,352,409,464,521,573,626,676$, 726, 775 and $867 \mu$ mol photons $\mathrm{m}^{-2} \mathrm{~s}^{-1}$ ). RLC measurements were made in triplicate. N-SSLC were constructed using 14 subsamples extracted from a dark-acclimated sample maintained in the dark at sampling temperature until the end of the N-SSLC measurement. These 14 subsamples were one after another exposed to a light step of different intensity $(14,53,80$, $94,145,175,236,295,352,464,521,626,726$ or $867 \mu \mathrm{mol}$ photons $\mathrm{m}^{-2} \mathrm{~s}^{-1}$ ) for $5 \mathrm{~min}$. Because of their long duration, N-SSLC were measured without any replication. Intensity of 
each light step (E) was obtained using the Spherical Micro Quantum Sensor US-SQS (Heinz Walz GmbH, Effeltrich, Germany). The fluorescence terminology follows van Kooten and Snel (1990).

At each light step, the fluorescence levels before and after applying a saturating pulse (200 $\mathrm{ms}$ up to $4,000 \mu \mathrm{mol}$ photons $\mathrm{m}^{-2} \mathrm{~s}^{-1}$ at $655 \mathrm{~nm}$ ) were measured with 4 pulse-modulated measuring lights peaking at 470, 520, 645 and $665 \mathrm{~nm}$. It was preliminary checked that this saturating pulse intensity and duration were appropriate to reach the maximal fluorescence levels $\left(F_{m}\right.$ or $F_{m}$ ') using the "View Pulse" function of the Phytowin software associated with the Phyto-PAM to examine the fluorescence kinetics during the saturating pulse. The effective quantum yield of photosystem II (ФPSII also noted $\Delta \mathrm{F} / \mathrm{F}_{\mathrm{m}}{ }^{\prime}$ ) was calculated for each measuring wavelength according to Genty et al. (1989) :

$$
\text { ФPSII }=\frac{\Delta \mathrm{F}}{\mathrm{F}_{\mathrm{m}}{ }^{\prime}}=\frac{\left(\mathrm{F}_{\mathrm{m}}{ }^{\prime}-\mathrm{F}\right)}{\mathrm{F}_{\mathrm{m}}{ }^{\prime}}
$$

where $\mathrm{F}$ is the fluorescence level of the light-acclimated sample measured just prior to the saturating pulse and $\mathrm{F}_{\mathrm{m}}$ ' is the maximum fluorescence emitted by the light-acclimated sample after a saturating pulse.

ФPSII measured with the measuring light peaking at $470 \mathrm{~nm}$ was then selected to calculate the absolute electron transport rate (ETR):

$$
\mathrm{ETR}=\text { ФPSII } \times \mathrm{E} \times 0.5 \times \overline{\mathrm{a}}_{\text {phy }}^{*}
$$

where $\mathrm{E}$ ( $\mu \mathrm{mol}$ photons $\mathrm{m}^{-2} \mathrm{~s}^{-1}$ ) is the actinic irradiance, 0.5 is a multiplication factor because the transport of one electron requires two photons (one per photosystem) (Gilbert et al. 2000; Kromkamp and Forster 2003), $\overline{\mathrm{a}}_{\text {phy }}^{*}\left(\mathrm{~m}^{2}(\mathrm{mg} \mathrm{chl} a)^{-1}\right)$ is the spectrally averaged (400$700 \mathrm{~nm}$ ) chlorophyll $a$ specific absorption coefficient (see below for its measurement). The measuring light peaking at $470 \mathrm{~nm}$ was chosen because it was the most appropriate to the English Channel's phytoplankton communities but also because almost all commercially available PAM and FRRF fluorometers are equipped with blue excitation lights.

ETR vs. E curves were fitted using the model of Webb et al. (1974) to estimate the maximal light utilization efficiency $(\alpha)$ which corresponds to the initial slope of the curve, the maximum electron transport rate $\left(\mathrm{ETR}_{\mathrm{m}}\right)$ which is the asymptote of the curve and the light saturation coefficient $\left(E_{k}\right)$ calculated as $\mathrm{ETR}_{\mathrm{m}} / \alpha$. As described in Lefebvre et al. (2011), curve fitting was achieved using the downhill simplex method of the Nelder-Mead model (1965), and standard deviation of parameters was estimated by an asymptotic method. All fittings were tested by analyses of variance $(\mathrm{P}<0.001)$, residues being tested for normality and 
homogeneity of variance, and parameters significance by Student's t-test $(\mathrm{P}<0.05)$. All the curve fitting processes and associated statistics were coded under MATLAB R2010b.

At each light step, the non-photochemical quenching of fluorescence (NPQ) was calculated from the fluorescence levels measured with the measuring light peaking at $470 \mathrm{~nm}$ using the equation proposed by Serôdio et al. (2005a):

$$
\mathrm{NPQ}=\frac{\left(\mathrm{F}_{\mathrm{m}}^{\prime} \mathrm{m}^{\prime} \mathrm{F}_{\mathrm{m}}{ }^{\prime}\right)}{\mathrm{F}_{\mathrm{m}}{ }^{\prime}}
$$

where $F_{m}{ }^{\prime} m$ is the maximum $F_{m}$ ' value, higher than $F_{m}$, that is measured under low actinic irradiance. NPQ vs. E curves were fitted using the model of Serôdio and Lavaud (2011) modified to directly extract the physiological parameter "S" corresponding to the slope of the first part of NPQ vs. E curves i.e. the part of the curve where NPQ increases monotonically with irradiance:

$$
N P Q=N P Q s a t \frac{E^{n}}{\left(\frac{N P Q s a t}{S}\right)^{n}+E^{n}}
$$

where $\mathrm{E}\left(\mu \mathrm{mol}\right.$ photons $\left.\mathrm{m}^{-2} \mathrm{~s}^{-1}\right)$ is the actinic irradiance, NPQsat is the maximum NPQ value reached at saturation, $S$ is the slope of the first part of the curve and $n$ is the Hill coefficient characterizing the sigmoidicity of the curve. When $\mathrm{n}<1$, the curve has a saturation-like shape and increases asymptotically toward NPQsat while when $n>1$, the curve has a sigmoidal shape. Because, most of our NPQ vs E curves did not reach saturation within the range of irradiances tested, $\mathrm{NPQ}_{\max }$, which corresponds to the highest NPQ value measured during the ETR vs. E curve, was also extracted.

\section{Chlorophyll a and mean chl a-specific absorption coefficients}

Chlorophyll $a$ ( $\mathrm{chl} a$ ) concentrations were determined by filtering known volumes of water samples through Whatman $47 \mathrm{~mm}$ GF/F glass-fibre filters. The filters were stored at $80^{\circ} \mathrm{C}$ and subsequently extracted in $90 \%$ acetone. Chl $a$ concentration was evaluated by fluorometry using a Turner Designs fluorometer (Model 10-AU) calibrated using known concentrations of commercially purified chl $a$ (Sigma). The fluorescence was measured before and after acidification with HCl (Aminot and Kérouel 2004; Lorenzen 1966).

The mean chl $a$-specific absorption coefficients $\left(\overline{\mathrm{a}}_{\text {phy }}^{*}\right)$ were obtained by measuring the optical density (OD) spectrum of samples filtered on Whatman GF/F filters according to the method of Mitchell et al. (2003). The OD spectrum was measured on wet glass-fibre filter 
attached on a quartz glass plate between 300 and $800 \mathrm{~nm}$ with $0.5 \mathrm{~nm}$ increments using a dual beam spectrophotometer (UV-2450, Shimadzu). A clean filter wetted with ultra-filtered $(0.2$ $\mu \mathrm{m})$ sea water was used as a reference. The OD of the filtered sample was corrected for the optical path length across the filter and the algal deposit on top of it, yielding the OD corresponding to the same sample in suspension, using mean $\beta$-correction factors according to Mitchell (1990). The average OD between 750 and $800 \mathrm{~nm}$ was used to correct for scattering. The depigmented particle absorption spectrum was obtained after extraction of the pigments in a solution of $98 \%$ methanol. The spectral absorption coefficient for phytoplankton pigments, $a_{\text {phy }}(\lambda)$, was calculated by subtracting the depigmented particle absorption spectrum to the absorption coefficient of total filtered particles and was normalized to the chlorophyll $a$ concentration to obtain the chl $a$-specific absorption: $\mathrm{a}^{*}$ phy $(\lambda)$. Finally, the mean absorption coefficient between 400 and $700 \mathrm{~nm}, \overline{\mathrm{a}}^{*}$ phy in $\mathrm{m}^{2}(\mathrm{mg} \mathrm{chl} a)^{-1}$, was calculated.

\section{Statistical analyses}

An analysis of similarities (one-way ANOSIM, Clarke and Warwick 1994) was used to test the significance of differences in phytoplankton communities. The analysis was based on Euclidean similarity matrix and was performed using PRIMER 6 (PRIMER-E Ltd., Plymouth, UK).

Differences in environmental and photosynthetic parameters measured at high and low tide were evaluated using Student t-tests or their non parametric equivalent (the Mann Whitney U test) (Scherrer 2007). Comparisons of RLC and N-SSLC and their derived photosynthetic parameters were performed using the method of Ratkowski (1983) for non-linear models. This method was coded under MATLAB R2010b. Differences between NPQ photosynthetic parameters resulting from RLC and N-SSLC were evaluated using paired Student t-tests. Pearson's correlation analysis and simple linear regressions were performed to evaluate relationships between the photosynthetic parameters derived from RLC and N-SSLC. Simple linear regression lines were compared to the 1:1 relationship using an analysis of covariance (ANCOVA) (Scherrer 2007). To understand deviations between photosynthetic parameters extracted from RLC and N-SSLC, the ratios ETR $\mathrm{m}_{-} \mathrm{RLC}_{\mathrm{C}} / \mathrm{ETR}_{\mathrm{m}_{-} \mathrm{N}-\mathrm{SSLC}}, \alpha_{-} \mathrm{RLC} / \alpha_{-} \mathrm{N}-\mathrm{SSLC}$ and $\mathrm{E}_{\mathrm{k} \_\mathrm{RLC}} / \mathrm{E}_{\mathrm{k} \_\mathrm{N}-\mathrm{SSLC}}$ were calculated. Relationships between these ratios and environmental variables (that were scales i.e. centered and reduced) were then quantified using stepwise multiple linear regression analyses. The environmental variables tested were: incident PAR, 
Table 1 Physicochemical parameters at daily scale: range (minimum-maximum), mean (SE) and coefficient of variation (CV, \%)

\begin{tabular}{|c|c|c|c|c|c|c|c|c|c|c|c|c|c|c|c|c|c|}
\hline & $\begin{array}{l}\text { Day } \\
\text { length }\end{array}$ & PAR & & & & Temperatu & & & Salinity & & & $\mathrm{NO}_{2}^{-}+\mathrm{NO}_{3}^{-}$ & & & $\mathrm{Si}(\mathrm{OH})_{4}$ & & \\
\hline & & Range & m (SE) & $\mathrm{CV}$ & & Range & m (SE) & $\mathrm{CV}$ & Range & m (SE) & $\mathrm{CV}$ & Range & m (SE) & $\mathrm{CV}$ & Range & m (SE) & $\mathrm{CV}$ \\
\hline 28 January 2010 & 9h12 & $0-534$ & $126(110)$ & 87 & & $5.3-5.9$ & $5.7(0.2)$ & 4 & $29.80-33.30$ & $32.01(1.68)$ & 5 & $15.4-48.3$ & $29.1(12.1)$ & 42 & $2.2-6.7$ & $4.8(1.9)$ & 41 \\
\hline 18 March 2010 & $12 \mathrm{~h} 04$ & $0-613$ & $259(174)$ & 67 & & $6.0-9.0$ & $7.2(0.8)$ & 12 & $30.00-34.10$ & $33.24(1.32)$ & 4 & $0.1-5.4$ & $1.7(2.5)$ & 149 & $1.2-3.9$ & $2.5(1.3)$ & 55 \\
\hline 26 March 2010 & $12 \mathrm{~h} 31$ & $0-808$ & $352(263)$ & 75 & & $7.0-9.1$ & $8.2(0.76)$ & 9 & $32.00-33.80$ & $33.40(0.56)$ & 2 & $0.4-1.8$ & $0.8(0.5)$ & 61 & $1.3-4.2$ & $2.3(1.0)$ & 42 \\
\hline 23 July 2010 & $15 \mathrm{~h} 25$ & $0-960$ & $428(322)$ & 75 & & $17.0-21.0$ & $19.6(1.2)$ & 6 & $34.62-34.70$ & $34.69(0.03)$ & 0.1 & $0.1-1.3$ & $0.4(0.3)$ & 88 & $0.1-3.1$ & $1.1(0.9)$ & 83 \\
\hline \multirow[t]{3}{*}{29 July 2010} & $15 \mathrm{~h} 10$ & $0-1,202$ & 351 (289) & 82 & & $18.1-22.2$ & $19.6(1.3)$ & 7 & $34.72-34.80$ & $34.78(0.03)$ & 0.1 & $0.3-2.5$ & $1.2(0.9)$ & 72 & $0.5-2.8$ & $1.6(0.8)$ & 53 \\
\hline & $\begin{array}{l}\text { Day } \\
\text { length }\end{array}$ & $\mathrm{PO}_{4}^{3-}$ & & & & & & & & & & & & & & & \\
\hline & & Range & \multicolumn{2}{|c|}{ m (SE) } & $\mathrm{CV}$ & & & & & & & & & & & & \\
\hline 28 January 2010 & $9 \mathrm{~h} 12$ & $0.3-1.9$ & \multicolumn{2}{|c|}{$0.9(0.5)$} & 57 & & & & & & & & & & & & \\
\hline 18 March 2010 & $12 \mathrm{~h} 04$ & $0.6-1.0$ & \multicolumn{2}{|c|}{$0.8(0.2)$} & 18 & & & & & & & & & & & & \\
\hline 26 March 2010 & $12 \mathrm{~h} 31$ & $0.1-1.0$ & \multicolumn{2}{|c|}{$0.7(0.2)$} & 32 & & & & & & & & & & & & \\
\hline 23 July 2010 & $15 \mathrm{~h} 25$ & $1.1-1.6$ & \multicolumn{2}{|c|}{$1.2(0.1)$} & 10 & & & & & & & & & & & & \\
\hline 29 July 2010 & $15 \mathrm{~h} 10$ & $1.2-1.5$ & \multicolumn{2}{|c|}{$1.3(0.1)$} & 9 & & & & & & & & & & & & \\
\hline
\end{tabular}

PAR: incident irradiance ( $\mu$ mol photons $\left.\mathrm{m}^{-2} \mathrm{~s}^{-1}\right)$, temperature: water temperature $\left({ }^{\circ} \mathrm{C}\right), \mathrm{NO}_{2}{ }^{-}+\mathrm{NO}_{3}{ }^{-}(\mu \mathrm{M}), \mathrm{Si}(\mathrm{OH})_{4}(\mu \mathrm{M}), \mathrm{PO}_{4}{ }^{3-}(\mu \mathrm{M}), \mathrm{SE}$ : standard error 
water temperature, nutrient concentrations $\left(\mathrm{NO}_{3}{ }^{-}+\mathrm{NO}_{2}{ }^{-}, \mathrm{Si}(\mathrm{OH})_{4}, \mathrm{PO}_{4}{ }^{3-}\right)$, salinity and assemblage composition (in term of chl $a$ concentration by groups and relative proportions of total biomass). Analyses were performed using R (R Core Team 2016). Linear models were built using the $\mathrm{lm}$ function and the most parsimonious model was identified using the stepAIC function from the MASS package (Venables and Ripley 2002). Environmental variables were included in the model using a stepwise selection and the model with the lowest Akaike score was selected. Significance of the selected model was then tested by F tests.

\section{Results}

Environmental parameters

During the study period, environmental factors to which phytoplankton were exposed allowed the comparison of RLC and N-SSLC under different conditions at daily scale as well as at annual scale.

At daily scale, maximum sea water temperature showed seasonal variations. It was low in January $\left(6^{\circ} \mathrm{C}\right)$, medium in March $\left(9^{\circ} \mathrm{C}\right)$ and high in July $\left(22^{\circ} \mathrm{C}\right)$ (Table 1$)$. During the day, sea water temperature increased by $0.6^{\circ} \mathrm{C}$ in January, $2-3{ }^{\circ} \mathrm{C}$ in March and $4^{\circ} \mathrm{C}$ in July. Different light conditions, representative of the natural hourly and daily variability, were encountered during the different sampling days. Light was the most variable parameter because it changed from hour to hour within each day and the intraday pattern of variation varied among the different sampling days. Day length and maximum daily irradiance varied according to seasons and increased from January to July. Because of the low depth of the sampling station, incident irradiance showed the same trends of variation as the mean light available within the water column and the water column was always within the photic zone (Houliez et al. 2013a; Houliez et al. 2013b). Salinity stayed relatively stable within the day and between the sampling days. During the day, nutrient concentrations increased with the flood of the tide and decreased with the ebb and changed between the sampling days according to seasons.

At annual scale, environmental parameters (i.e. irradiance, sea water temperature, salinity and nutrients) were not significantly different between high and low tides (Mann Whitney $\mathrm{U}$ test, $\mathrm{P}>0.05)$. Sea water temperature, irradiance, $\mathrm{NO}_{2}{ }^{-}+\mathrm{NO}_{3}{ }^{-}$and $\mathrm{Si}(\mathrm{OH})_{4}$ showed clear seasonal variations (Fig. 2). Sea water temperature and maximum incident irradiance followed the classical seasonal evolution of temperate northern regions with low values in 

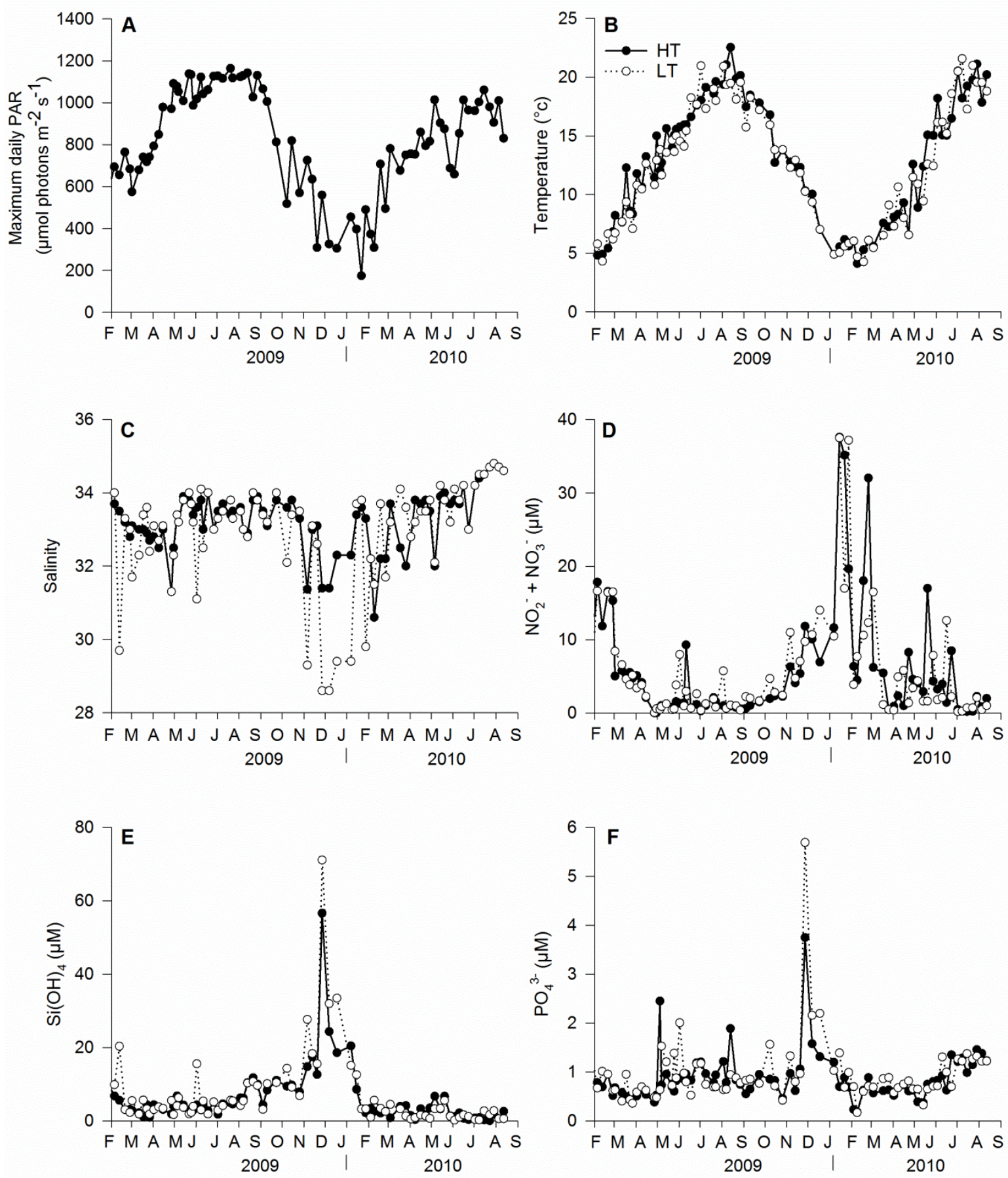

Fig. 2 Seasonal variability of physicochemical parameters. A) Maximum incident daily PAR ( $\mu$ mol photons $\mathrm{m}^{-2}$ $\left.\mathrm{s}^{-1}\right)$, B) Temperature $\left({ }^{\circ} \mathrm{C}\right)$, C) Salinity, D) Nitrite + nitrate concentration $\left(\mathrm{NO}_{2}^{-}+\mathrm{NO}_{3}^{-}, \mu \mathrm{M}\right)$, E) Silicate concentration $\left(\mathrm{Si}(\mathrm{OH})_{4}, \mu \mathrm{M}\right)$ and $\left.\mathrm{F}\right)$ Phosphate concentration $\left(\mathrm{PO}_{4}{ }^{3-}, \mu \mathrm{M}\right)$. HT: high tide. LT: low tide 
January - February (respectively $5^{\circ} \mathrm{C}$ and 200-300 $\mu \mathrm{mol}$ photons $\mathrm{m}^{-2} \mathrm{~s}^{-1}$ ) and high values in August (respectively $20-22^{\circ} \mathrm{C}$ and $1000-1100 \mu \mathrm{mol}$ photons $\mathrm{m}^{-2} \mathrm{~s}^{-1}$ ). $\mathrm{NO}_{2}{ }^{-}+\mathrm{NO}_{3}{ }^{-}$were high in February $2009(15 \mu \mathrm{M})$ and decreased rapidly between March and May 2009 to reach their lowest values between May and September 2009 (1-2 $\mu \mathrm{M})$. Si $(\mathrm{OH})_{4}$ were low between February and August 2009 (around $4 \mu \mathrm{M}$ ) and increased from the end of August 2009 to reach their maximum at the end of November 2009 (around $60 \mu \mathrm{M}$ ). A decrease in $\mathrm{Si}(\mathrm{OH})_{4}$ concentration was then observed between December 2009 and the end of January 2010 to reach a minimum between February and August 2010 (around $1 \mu \mathrm{M}$ ). $\mathrm{PO}_{4}{ }^{3-}$ did not follow the same seasonal pattern. $\mathrm{PO}_{4}{ }^{3-}$ concentrations stayed relatively stable between February and November 2009 (around $0.8 \mu \mathrm{M}$ ). They increased from November 2009 to reach their highest values in December 2009 (3.8-5.7 $\mu \mathrm{M})$, decreased between January and February 2010 to values around $0.8 \mu \mathrm{m}$ and finally stayed relatively stable from February to August 2010. Salinity ranged from 28.2 to 34.8 and showed no seasonal variation.

\section{Phytoplankton composition}

At daily scale, phytoplankton composition did not vary significantly during the day (ANOSIM, P>0.05) but different phytoplankton community structures were observed between the different sampling days according to the sampling season (ANOSIM, P<0.05) (Fig. 3A). On January $28^{\text {th }} 2010$, the community was composed of "diatoms + dinoflagellates" and "Cryptophyta + cyanobacteria" in almost equal proportions. March 2010 was the period when the Haptophyte Phaeocystis globosa bloomed. This species dominated phytoplankton community on March $18^{\text {th }}$ and $26^{\text {th }} 2010$ with a small contribution of "diatoms + dinoflagellates" and "Cryptophyta + cyanobacteria". On July $23^{\text {th }}$ and $29^{\text {th }} 2010, P$. globosa and "Cryptophyta + cyanobacteria" were present in almost equal proportions with a lower contribution of "diatoms + dinoflagellates". Total chl $a$ biomass was equal to $5 \mu \mathrm{g} . \mathrm{L}^{-1}$ in January 2010, 19-20 $\mu \mathrm{g} . \mathrm{L}^{-1}$ in March 2010 and $3 \mu \mathrm{g} . \mathrm{L}^{-1}$ in July 2010.

At annual scale, phytoplankton composition was not significantly different between high and low tides (ANOSIM, P>0.05). Phytoplankton community structure showed clear seasonal variations with different phytoplankton communities during the different seasons of the year (Fig. 3B). In spring 2009, there were three successive phytoplankton blooms. $P$. globosa bloomed from mid-April to mid-May and disappeared at the end of spring. This bloom was preceded and followed by two blooms of "diatoms + dinoflagellates" (a first 

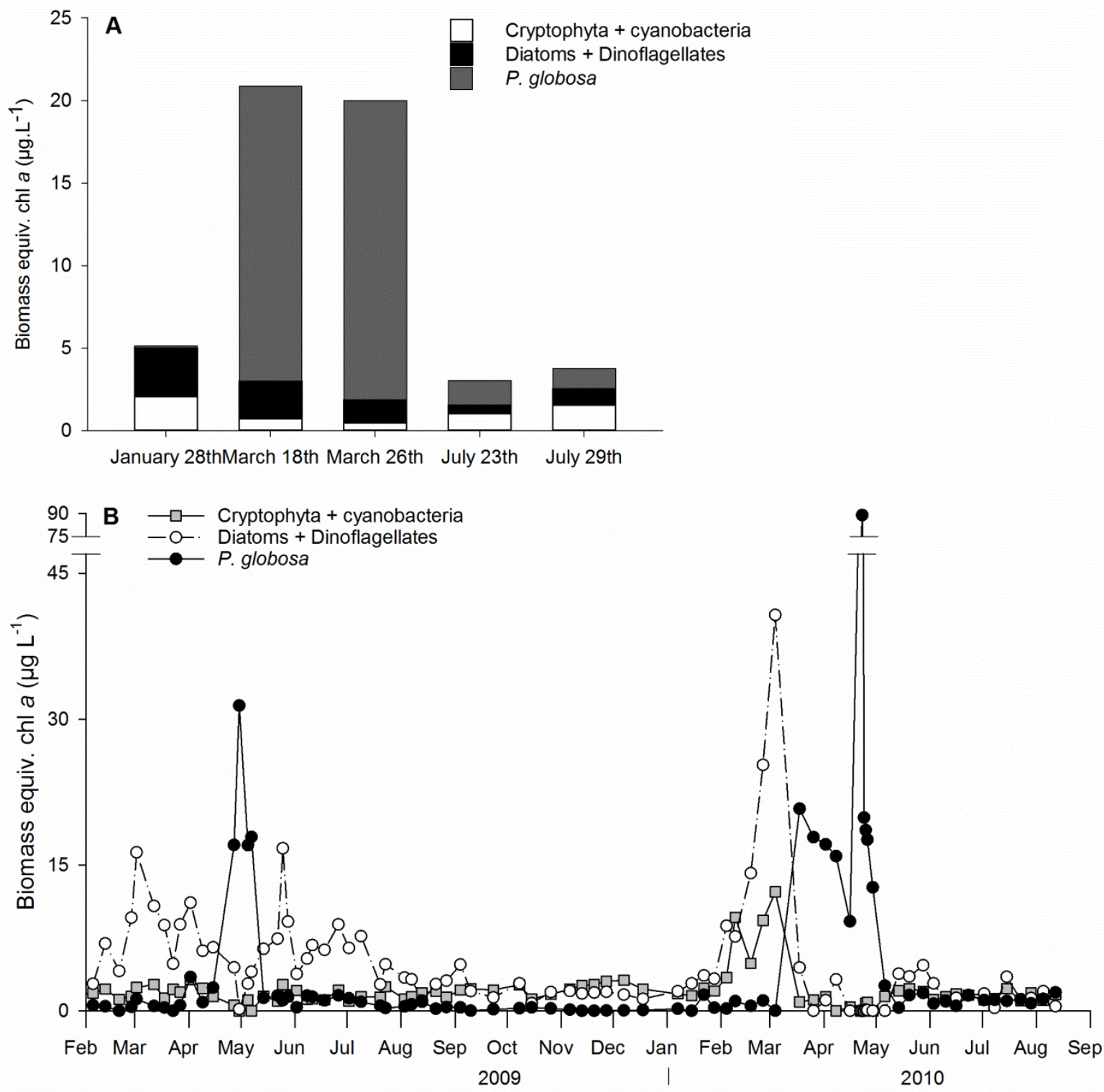

Fig. 3 A) Hourly and B) seasonal variability of taxonomic composition of phytoplankton assemblages identified by the FluoroProbe. The relative amount of each phytoplankton group is expressed in terms of the equivalent amount of chlorophyll $a$ per litre. Values for the seasonal variability are the mean of measurements made at high and low tide 
bloom from February to mid-April and a second bloom from May to August). In 2010, $P$. globosa bloom started earlier (from mid-March) and reached a maximum of biomass 2.8 times higher than in 2009. This bloom was preceded by a "diatoms + dinoflagellates" bloom (between February and March) but contrary to 2009, was not followed by a second bloom of "diatoms + dinoflagellates". The "diatoms + dinoflagellates" bloom preceding the $P$. globosa bloom in 2010 had a maximum of biomass 2.5 times higher than in 2009. "Cryptophyta + cyanobacteria" were present throughout the year. In 2009, their concentration always stayed low while in 2010, a bloom of "Cryptophyta + cyanobacteria" was observed at the same time of the "diatoms + dinoflagellates" bloom (in February-March).

ETR vs. E curves and derived photosynthetic parameters $\left(\alpha, E T R_{m}\right.$ and $\left.E_{k}\right)$
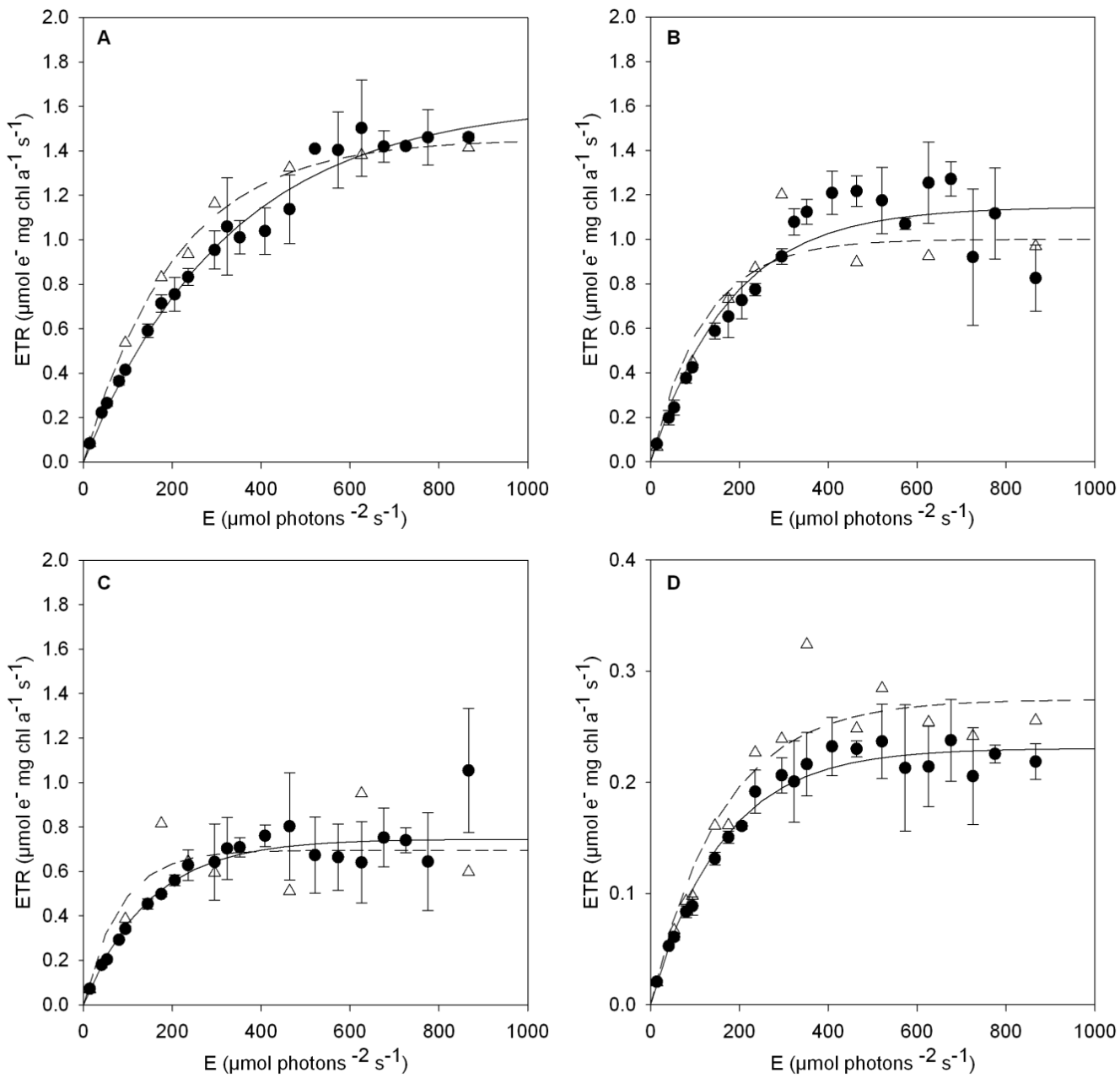

Fig. 4 Examples of ETR vs. E curves obtained after RLC and N-SSLC measurements at daily scale on A) July $\left.29^{\text {th }} 6 \mathrm{~h} 45 \mathrm{am}, \mathrm{B}\right)$ July $\left.29^{\text {th }} 8 \mathrm{~h} 30 \mathrm{am}, \mathrm{C}\right)$ July $29^{\text {th }} 8 \mathrm{~h} 45 \mathrm{pm}$ and D) at seasonal scale on May $20^{\text {th }}$ at low tide. Black circles and solid line correspond to RLC. RLC values are mean \pm standard deviation of 3 replicates. White triangles and dashed line are N-SSLC 
At daily scale, the shape of ETR vs E curves differed between RLC and N-SSLC and changed during the day (Fig. 4A, B, C). The photosynthetic parameters resulting from RLC and N-SSLC varied during the day without any diel pattern common to the different sampling days. The maximal light utilization efficiency derived from RLC $\left(\alpha_{-}\right.$RLC $)$and N-SSLC $\left(\alpha_{-} \mathrm{N}-\right.$ SSLC) (Fig. 5A) showed very similar patterns of variation during the day and their values were not significantly different regardless of the sampling date considered (Ratkowski test for nonlinear models, $\mathrm{P}>0.05$ ). By contrast, the degree of resemblance between the maximum electron transport rate $\left(\mathrm{ETR}_{\mathrm{m}}\right)\left(\right.$ Fig. 5B) or light saturation coefficient $\left(\mathrm{E}_{\mathrm{k}}\right)($ Fig. 5C) derived from N-SSLC and RLC differed from one day to another. On January $28^{\text {th }}$, March $18^{\text {th }}$, July $23^{\text {th }}$ and July $29^{\text {th }}$, ETR $_{\mathrm{m}}$ derived from N-SSLC $\left(\mathrm{ETR}_{\mathrm{m} \_\mathrm{N}-\mathrm{SSLC}}\right)$ and from RLC (ETR $\left.\mathrm{m}_{-} \mathrm{RLC}\right)$ showed similar patterns of variation. ETR $_{\mathrm{m} \_\mathrm{N}-\mathrm{SSLC}}$ was significantly higher than $\mathrm{ETR}_{\mathrm{m} \_\mathrm{RLC}}$ (Ratkowski test for non-linear models, $\mathrm{P}<0.05$ ) only at the first and last sampling hours on January $28^{\text {th }}$ and throughout the day on July $23^{\text {th }}$. On March $26^{\text {th }}, \mathrm{ETR}_{\mathrm{m} \_ \text {RLC }}$ increased more rapidly to follow light variations than $\mathrm{ETR}_{\mathrm{m} \_\mathrm{N}-\mathrm{SSLC}}$ which increased latter. At $12 \mathrm{~h} 00$, $\mathrm{ETR}_{\mathrm{m} \_\mathrm{RLC}}$ was thus significantly higher than $\mathrm{ETR}_{\mathrm{m} \_\mathrm{N}-\mathrm{SSLC}}$ while at $13 \mathrm{~h} 45$, it was the opposite (Ratkowski test for non-linear models, $\mathrm{P}<0.05)$. $\mathrm{E}_{\mathrm{k}}$ derived from RLC $\left(\mathrm{E}_{\mathrm{k} \_\mathrm{RLC}}\right)$ followed more closely light variations than $\mathrm{E}_{\mathrm{k}}$ derived from N-SSLC ( $\left.\mathrm{E}_{\mathrm{k} \_\mathrm{N}-\mathrm{SSLC}}\right)$ on January $28^{\text {th }}$ and on March $18^{\text {th }}$ and $26^{\text {th }}$. By contrast, on July $23^{\text {th }}$ and $29^{\text {th }}$, no significant difference was found between $\mathrm{E}_{\mathrm{k} \_ \text {RLC }}$ and $\mathrm{E}_{\mathrm{k} \_\mathrm{N}-\mathrm{SSLC}}$. Ratios $\mathrm{ETR}_{\mathrm{m} \_ \text {RLC }} / \mathrm{ETR}_{\mathrm{m} \_\mathrm{N}-\mathrm{SSLC}}$ and $\mathrm{E}_{\mathrm{k} \_ \text {RLC }} / \mathrm{E}_{\mathrm{k} \_\mathrm{N}-\mathrm{SSLC}}$ were related to temperature, phytoplankton composition and light conditions experienced before the measurement (Table 2).

At annual scale, the shape of ETR vs E curves was very similar between RLC and NSSLC (Fig. 4D). Photosynthetic parameters were not significantly different between high and low tides (Student t-test, P>0.05). Patterns of variation of $\alpha$ (Fig. 6A) and $\mathrm{ETR}_{\mathrm{m}}$ (Fig. 6B) derived from N-SSLC and RLC were very similar at high tide as well as at low tide. $\mathrm{ETR}_{\mathrm{m} \_\mathrm{RLC}}, \mathrm{ETR}_{\mathrm{m} \_\mathrm{N}-\mathrm{SSLC}}, \alpha_{\_} \mathrm{RLC}$ and $\alpha_{-} \mathrm{N}-\mathrm{SSLC}$ showed a similar high variability without any clear seasonal cycle with high values in summer, late autumn-early winter and punctually during spring. However in term of absolute values, significant differences were found between RLC and N-SSLC photosynthetic parameters (Ratkowski test for non-linear models, $\mathrm{P}<0.05$ ). ETR $_{\mathrm{m}}$ and $\alpha$ were generally significantly higher when measured with N-SSLC than after RLC measurements. ETR $\mathrm{m}_{\mathrm{m} \_\mathrm{N}-\mathrm{SSLC}}$ ranged from 0.02 to $3.78 \mu \mathrm{mol} \mathrm{e}^{-} \mathrm{mg}$ chl $a^{-1} \mathrm{~s}^{-1}$ while ETR $\mathrm{m}_{-} \mathrm{RLC}$ ranged from 0.01 to $2.72 \mu \mathrm{mol} \mathrm{e}^{-} \mathrm{mg} \operatorname{chl} a^{-1} \mathrm{~s}^{-1}$. $\alpha_{-} \mathrm{N}$-SSLC ranged from 0.0001 to $0.0172 \mu \mathrm{mol}$ $\mathrm{e}^{-} \mathrm{mg} \operatorname{chl} a^{-1} \mathrm{~s}^{-1}$ ( $\mu \mathrm{mol}$ photons $\left.\mathrm{m}^{-2} \mathrm{~s}^{-1}\right)^{-1}$ while $\alpha_{-}$RLC ranged from 0.0001 to $0.0132 \mu \mathrm{mol} \mathrm{e}^{-} \mathrm{mg}$ 
Manuscript published in Marine Biology

The final version is available on the publisher's website https://doi.org/10.1007/s00227-017-3208-8

Table 2 Stepwise multiple linear regression equations and their associated statistics relating ratios of photosynthetic parameters derived from RLC and N-SSLC to environmental factors and phytoplankton composition. $\mathrm{r}^{2}=$ adjusted coefficient of determination (in \%), PAR $4 \mathrm{D}$ : mean incident PAR over the three previous days and day of sampling, Phaeo: Phaeocystis globosa biomass (FluoroProbe estimation)

\begin{tabular}{|c|c|c|c|c|c|}
\hline & Regression equation & $\mathrm{r}^{2}$ & $\mathrm{~F}$ & $P$ & $\mathrm{n}$ \\
\hline \multirow{2}{*}{ Daily scale } & $\mathrm{ETR}_{\mathrm{m} \_ \text {RLC }} / \mathrm{ETR}_{\mathrm{m} \_\mathrm{N}-\mathrm{SSLC}}=-0.10+0.13 \times$ temp. $+0.10 \times$ Phaeo $-0.01 \times \mathrm{PAR}_{4 \mathrm{D}}$ & 21.5 & 4.92 & 0.005 & 44 \\
\hline & $E_{k \_R L C} / E_{k \_N-S S L C}=-0.19+0.14 \times$ temp. $+0.10 \times$ Phaeo $-7.47 E-03 \times P A_{4 D}$ & 22.2 & 5.09 & 0.004 & 44 \\
\hline Annual scale & $\alpha_{-R L C} / \alpha_{-N-S S L C}=1.10-0.07 \times$ temp. $-0.05 \times$ Phaeo & 21.0 & 15.72 & $<0.001$ & 112 \\
\hline
\end{tabular}




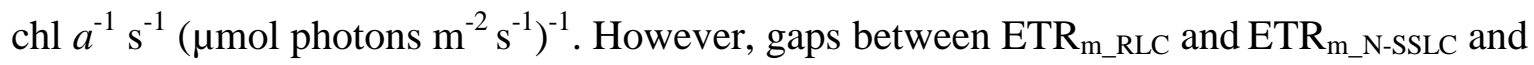
between $\alpha_{\_}$RLC and $\alpha_{-}$N-SSLC varied during the year. $E_{\mathrm{k}_{-} N-S S L C}$ and $E_{\mathrm{k}_{-} \text {RLC }}$ did not show exactly the same pattern of variation (Fig. 6C). At some dates, $\mathrm{E}_{\mathrm{k} \_\mathrm{N}-\mathrm{SSLC}}$ was higher than $\mathrm{E}_{\mathrm{k} \_\mathrm{RLC}}$ while at other dates it was lower but in term of absolute values, $\mathrm{E}_{\mathrm{k}_{-} \mathrm{N}-\mathrm{SSLC}}$ and $\mathrm{E}_{\mathrm{k} \_ \text {RLC }}$ were very close. $\mathrm{E}_{\mathrm{k} \_\mathrm{N}-\mathrm{SSLC}}$ ranged from 72 to $407 \mu \mathrm{mol}$ photons $\mathrm{m}^{-2} \mathrm{~s}^{-1}$ while $\mathrm{E}_{\mathrm{k} \_ \text {RLC }}$ ranged from 83 to $402 \mu \mathrm{mol}$ photons $\mathrm{m}^{-2} \mathrm{~s}^{-1}$. Ratio $\alpha \_$RLC $/ \alpha \_\mathrm{N}-\mathrm{SSLC}$ was related to temperature and phytoplankton composition (Table 2) while no relationships could be found between the environmental factors investigated and ratios $\mathrm{ETR}_{\mathrm{m} \_\mathrm{RLC}} / \mathrm{ETR}_{\mathrm{m} \_\mathrm{N}-\mathrm{SSLC}}$ and $\mathrm{E}_{\mathrm{k}_{\_} \mathrm{RLC}} / \mathrm{E}_{\mathrm{k} \_\mathrm{N}-\mathrm{SSLC}}$.

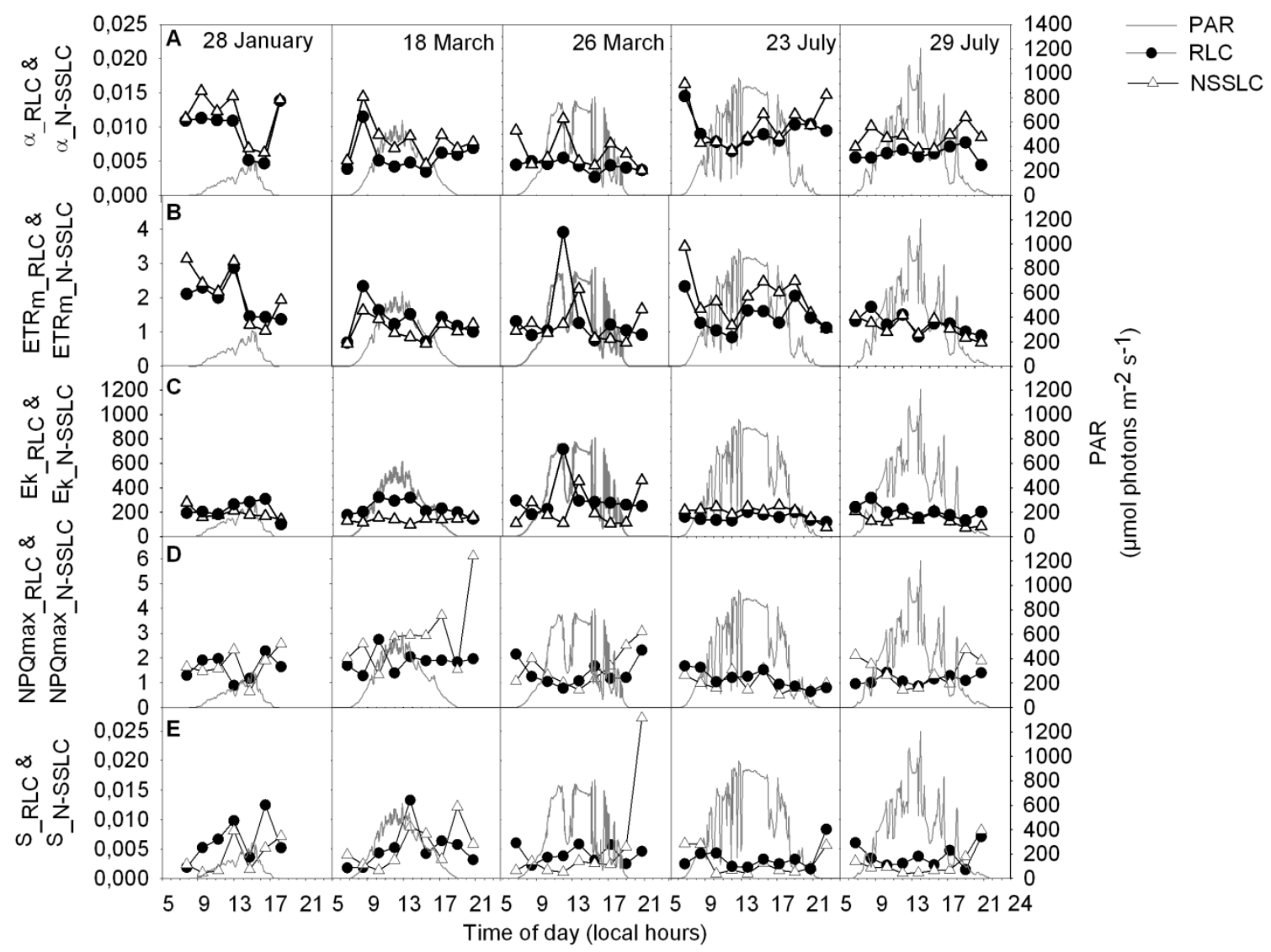

Fig. 5 Photosynthetic parameters measured with RLC and N-SSLC at daily scale. A) Maximal light utilization efficiency ( $\alpha$ in $\mu \mathrm{mol}$ e- $\left.\mathrm{mg} \mathrm{chl} \mathrm{a} \mathrm{s}^{-1}\left(\mu \mathrm{mol} \text { photons } \mathrm{m}^{-2} \mathrm{~s}^{-1}\right)^{-1}\right)$, B) Maximum electron transport rate $\left(\mathrm{ETR}_{\mathrm{m}}\right.$ in $\mu$ mol e- mg chl a $\left.\left.\mathrm{a}^{-1} \mathrm{~s}^{-1}\right), \mathrm{C}\right)$ Light saturation coefficient $\left(\mathrm{E}_{\mathrm{k}}\right.$ in $\mu \mathrm{mol}$ photons $\left.\mathrm{m}^{-2} \mathrm{~s}^{-1}\right)$, D) Maximum level of nonphotochemical quenching reached during the curve (NPQmax) and E) Slope of the first part of the NPQ vs. E curve (S) (in black and white) and incident PAR ( $\mu$ mol photons $\left.\mathrm{m}^{-2} \mathrm{~s}^{-1}\right)$ in gray 


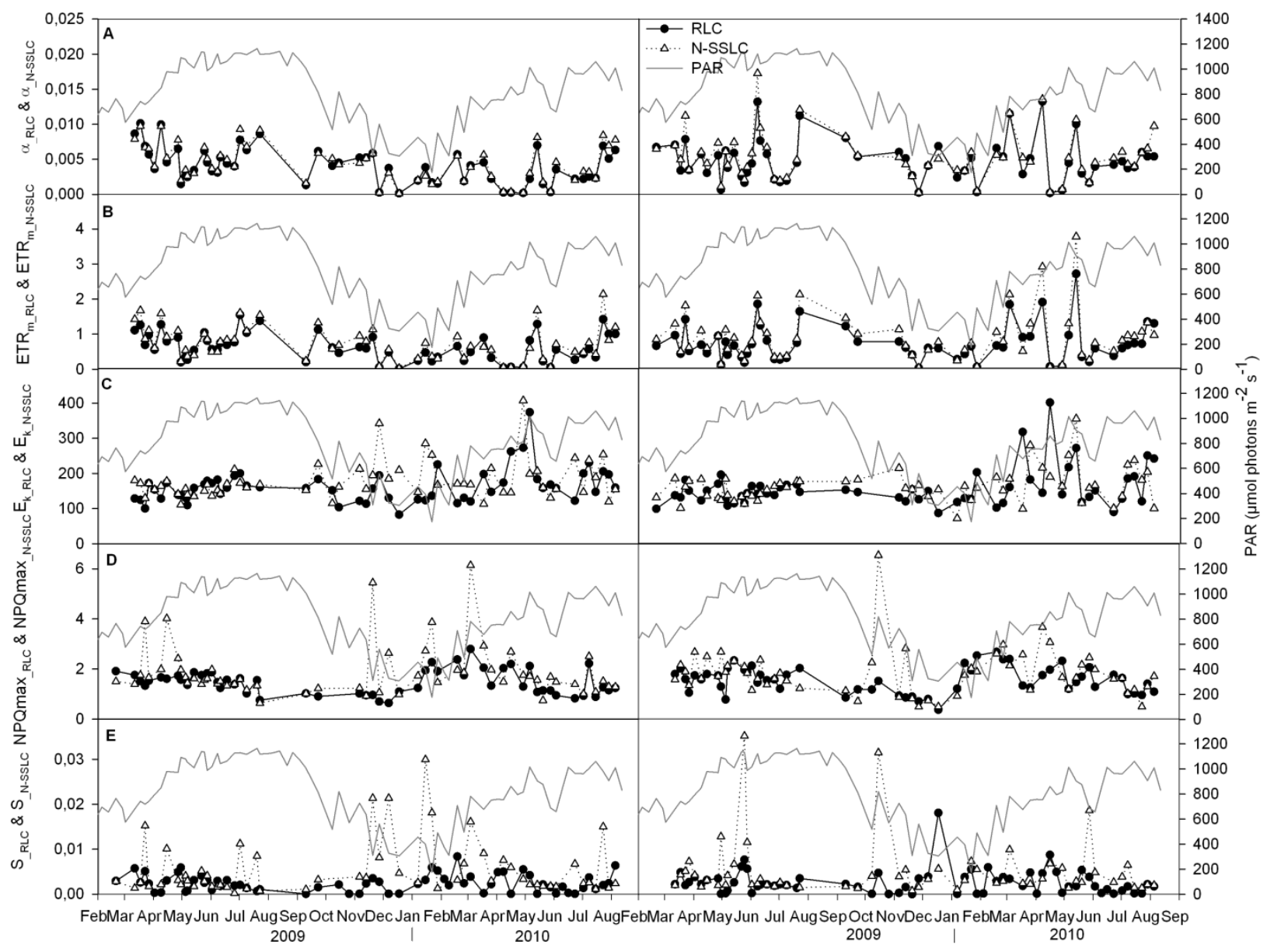

Fig. 6 Photosynthetic parameters measured with RLC and N-SSLC at annual scale and at high and low tide. A) Maximal light utilization efficiency $(\alpha)$, B) Maximum electron transport rate $\left(\mathrm{ETR}_{\mathrm{m}}\right)$, C) Light saturation coefficient $\left.\left(\mathrm{E}_{\mathrm{k}}\right), \mathrm{D}\right)$ Maximum level of non-photochemical quenching reached during the curve (NPQmax), E) Slope of the first part of the NPQ vs. E curve (S) (in black and white) and incident PAR ( $\mu$ mol photons $\mathrm{m}^{-2} \mathrm{~s}^{-1}$ ) in gray. Left panel: low tide. Right panel: high tide 


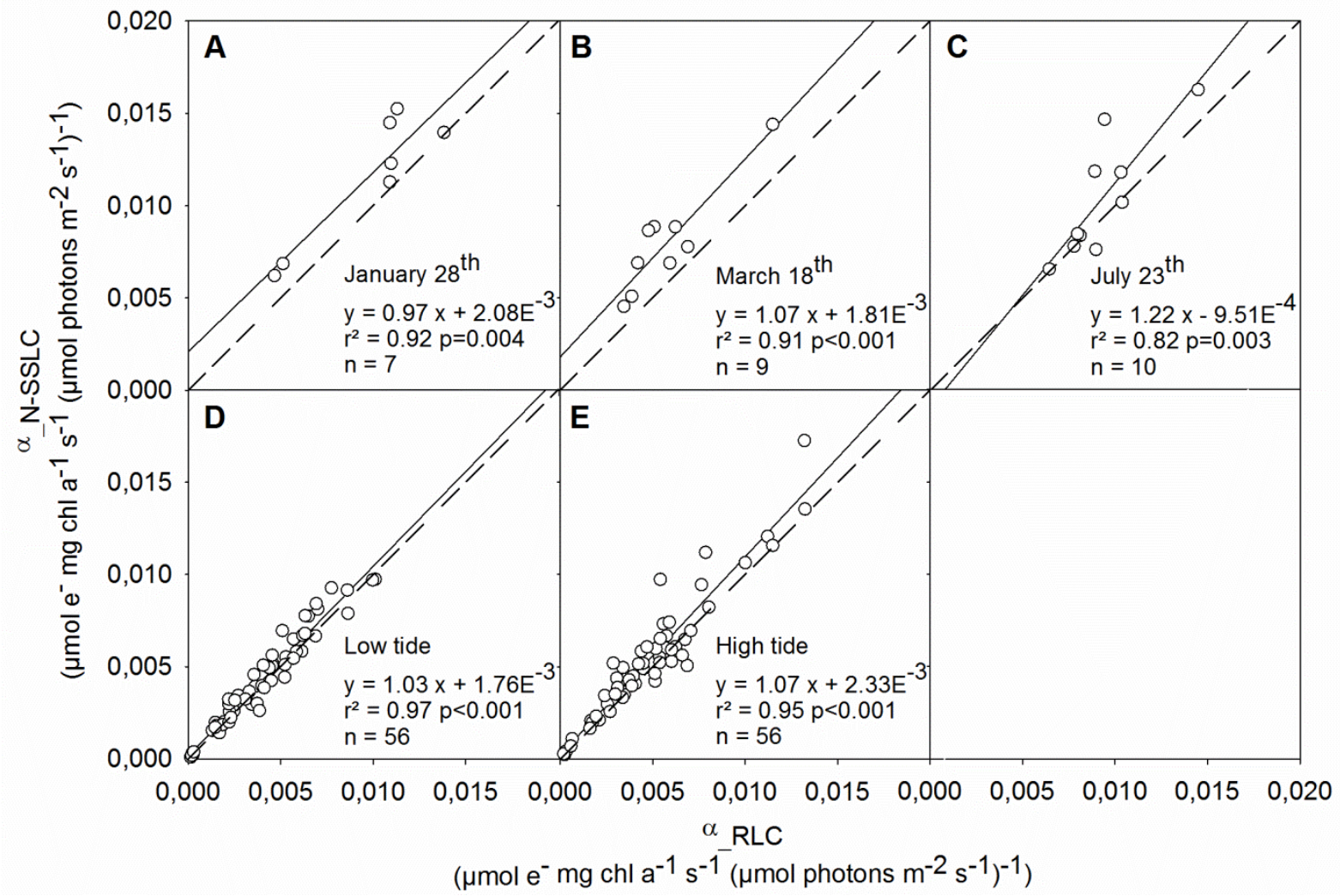

Fig. 7 Linear relationship between $\alpha_{\mathrm{N}-\mathrm{SSLC}}$ and $\alpha_{\text {RLC }}$ measured at daily (A, B, C) and annual (D, E) scales. The solid line is the regression line. The dashed line represents the 1:1 ratio

At daily scale, with the exception of March $26^{\text {th }}$ and July $29^{\text {th }}$, significant linear relationships very close to the 1:1 relationship were found between $\alpha_{-}$N-SSLC and $\alpha_{-}$RLC (Fig. $7 \mathrm{~A}, \mathrm{~B}, \mathrm{C})$. On July $23^{\text {th }}$, this relationship was indeed not significantly different from a 1:1 relationship (ANCOVA, $\mathrm{P}=0.19$ ). On January $28^{\text {th }}$ and March $18^{\text {th }}$, the slope was not significantly different from 1 (ANCOVA, January $28^{\text {th }} \mathrm{P}=0.89$, March $18^{\text {th }} \mathrm{P}=0.71$ ) but the intercept was significantly different from zero (ANCOVA, $\mathrm{P}<0.05$ ). The quality of the relationship between $\mathrm{ETR}_{\mathrm{m} \_\mathrm{RLC}}$ and $\mathrm{ETR}_{\mathrm{m} \_\mathrm{N}-\mathrm{SSLC}}$ differed between sampling days (Fig. 8A, B, C, D). On March $26^{\text {th }}$, no significant linear relationship was found between $E_{T R} R_{m_{-} R L C}$ and

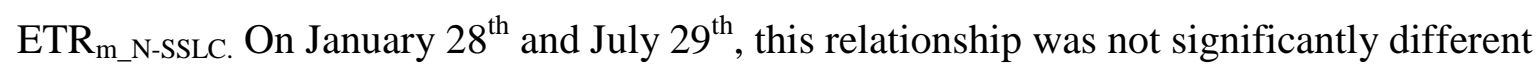
from the 1:1 relationship (ANCOVA, $\mathrm{P}=0.50$ ). On March $18^{\text {th }}$, the relationship was significant but different from a 1:1 relationship because the slope was less than 1 (ANCOVA, P<0.05). On July $23^{\text {th }}$, the relationship was very close to a 1:1 relationship. The slope was not significantly different from 1 (ANCOVA, $\mathrm{P}=0.20$ ). Only the intercept was significantly different from zero (ANCOVA, $\mathrm{P}<0.001$ ). 
At annual scale, significant linear relationships were found between $\alpha_{\text {N-SSLC }}$ and $\alpha_{\text {RLC }}$ (Fig. 7D and E) and between ETR $_{\mathrm{m}_{-} \mathrm{N}-\mathrm{SSLC}}$ and $\mathrm{ETR}_{\mathrm{m} \_ \text {RLC }}($ Fig. 8E and F) and at high tide and low tide. The relationship between $\alpha_{-}$N-SSLC and $\alpha_{-}$RLC was very close to a 1:1 relationship with a slope not significantly different from 1 (ANCOVA, low tide $\mathrm{P}=0.45$, high tide $\mathrm{P}=0.13$ ). Only the intercept was significantly different from zero (ANCOVA, low tide $\mathrm{P}<0.05$, high tide $\mathrm{P}<0.001)$. The relationship between $\mathrm{ETR}_{\mathrm{m} \_\mathrm{N}-\mathrm{SSLC}}$ and $\mathrm{ETR}_{\mathrm{m} \_\mathrm{RLC}}$ was significantly different from a 1:1 relationship (ANCOVA, low tide and high tide $\mathrm{P}<0.001$ ) with a slope significantly higher than 1 at high tide and low tide (ANCOVA, low tide $\mathrm{P}<0.05$, high tide $\mathrm{P}<0.001)$

At daily scale as well as at annual scale, no significant linear relationship was found between $\mathrm{E}_{\mathrm{k} \_\mathrm{N}-\mathrm{SSLC}}$ and $\mathrm{E}_{\mathrm{k} \_ \text {RLC. }}$.

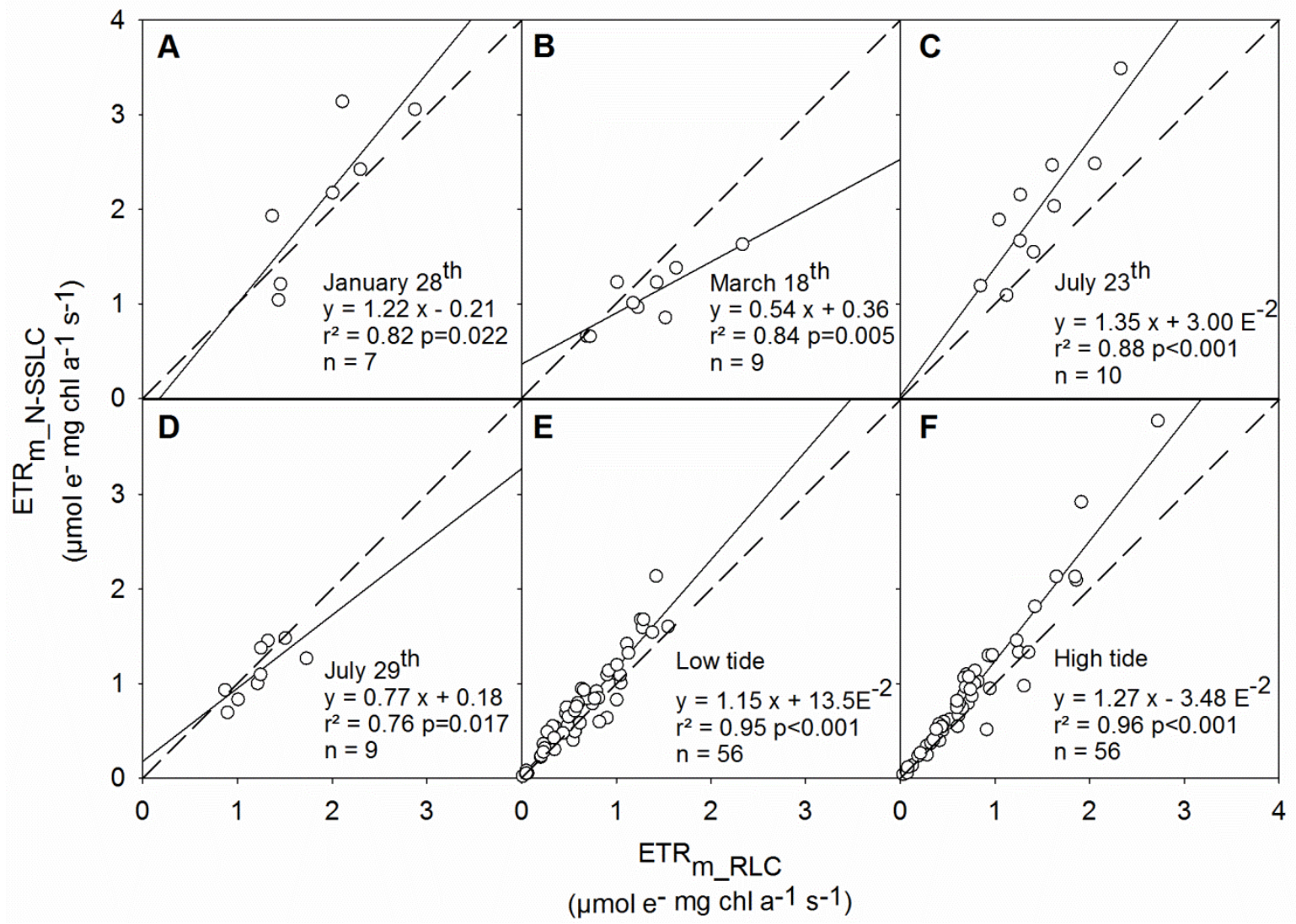

Fig. 8 Linear relationship between $\mathrm{ETR}_{\mathrm{m} \_\mathrm{RLC}}$ and $\mathrm{ETR}_{\mathrm{m} \_\mathrm{N}-\mathrm{SSLC}}$ measured at daily $(\mathrm{A}, \mathrm{B}, \mathrm{C}, \mathrm{D})$ and annual $(\mathrm{E}, \mathrm{F})$ scales. The solid line is the regression line. The dashed line represents the 1:1 ratio

Non-photochemical quenching $(N P Q)$

At daily scale, the shape of NPQ vs. E curves was very similar when measured with RLC or N-SSLC. At the beginning of the curve, NPQ was close to zero and then increased 
monotonically with increasing light steps. $48 \%$ of NPQ vs. E curves did not reach saturation within the range of irradiances applied. Their shape was close to linear with a sigmoidicity equal to 1 (Fig. 9A). The $52 \%$ remaining reached saturation but sigmoidicity was also close to 1 (Fig. 9B). The maximum level of NPQ reached during the curve $\left(\mathrm{NPQ}_{\max }\right)$ and the slope of the first part of the NPQ vs. E curve (S) (Fig. 5D, E) were not significantly different between RLC and N-SSLC (Paired t-test, P>0.05) even though they did not always follow the same trends of variation during the day.

At annual scale, the shape of NPQ vs. E curves was also very similar between RLC and N-SSLC and was the same as at daily scale. $74 \%$ of NPQ vs. E curves were close to linear and did not reach saturation. The $26 \%$ remaining reached saturation but their sigmoidicity was also close to $1 . \mathrm{NPQ}_{\max }$ and $\mathrm{S}$ (Fig. 6D, E) were not significantly different between high and low tide whatever the methodology employed (Student t-test, $\mathrm{P}>0.05$ ). NPQ max_N-SSLC $_{\text {and }} \mathrm{S}_{-} \mathrm{N}-$ SSLC were significantly higher than $\mathrm{NPQ}_{\text {max_RLC }}$ and $\mathrm{S}_{-}$RLC $($Paired t-test, $\mathrm{P}<0.05$ ) and they showed several peaks that did not appear in NPQ $\max _{-}$RLC and $S_{-}$RLC variations.
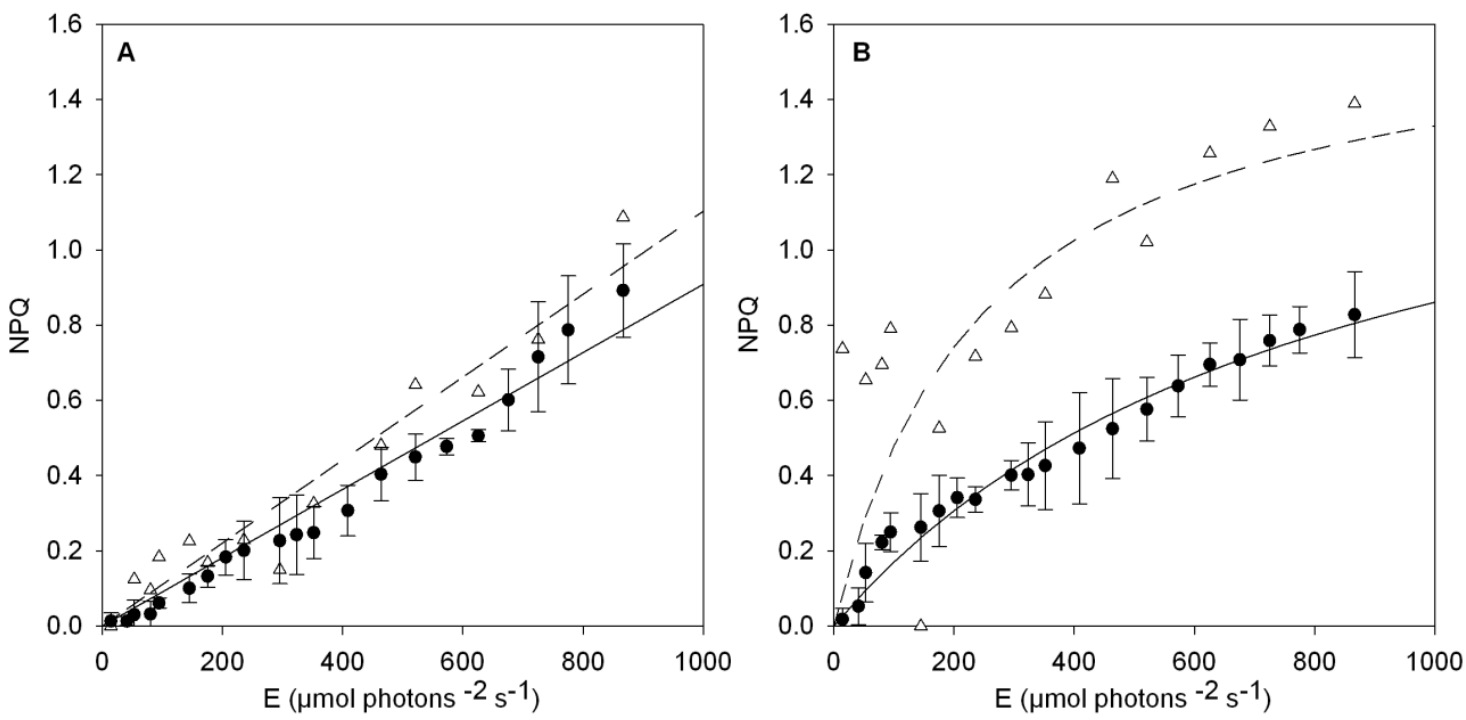

Fig. 9 The two main shapes of NPQ vs. E curves observed at daily and seasonal scales. A) Shape close to linear with a sigmoidicity equal to 1 and saturation not reached within the range of irradiances applied. B) Saturation reached and sigmoidicity close to 1 . Black circles and solid line correspond to RLC. RLC values are mean \pm standard deviation of 3 replicates. White triangles and dashed line are N-SSLC 


\section{Discussion}

Variations at different time scales of $\alpha_{-} R L C, E T R_{m_{-} R L C}, E_{k_{-} R L C} v e r s u s \alpha_{-} N-S S L C, E T R_{m \_N-S S L C}$ and $E_{k \_N-S S L C}$

The level of similarity between the photosynthetic parameters extracted from RLC and N-SSLC differed according to the time scale and parameter considered. The highest level of dissimilarity was observed at daily scale due to the recent light history which had more influence on the photosynthetic parameters resulting from RLC than N-SSLC. As a consequence, at daily scale, $\mathrm{ETR}_{\mathrm{m} \_\mathrm{RLC}}$ and $\mathrm{E}_{\mathrm{k} \_\mathrm{RLC}}$ followed more closely rapid light variations than $\mathrm{ETR}_{\mathrm{m} \_\mathrm{N}-\mathrm{SSLC}}$ and $\mathrm{E}_{\mathrm{k} \_\mathrm{N}-\mathrm{SSLC}}$ did and some rapid changes in phytoplankton photosynthetic activity were not detected when the measurements were made with N-SSLC. These observations are in accordance with studies made on microphytobenthos showing that patterns of variation and absolute values of photosynthetic parameters are influenced by the duration of light steps (Frankenbach and Serôdio 2017; Herlory et al. 2007; Lefebvre et al. 2011; Perkins et al. 2006). Differences between photosynthetic parameters measured on microphytobenthic algae grown under experimental high light or low light conditions have thus been shown to decrease as a function of increasing duration of light steps. As a result, SSLC can reduce or negate the real level of the previous 1 hour photoacclimation while RLC with short light steps keep this difference (Frankenbach and Serôdio 2017; Perkins et al. 2006). These results have important implications for the design of future phytoplankton photosynthesis studies at daily scale because they show that N-SSLC may not be appropriate to accurately measure phytoplankton responses to short-term environmental variations. Indeed, some of the phytoplankton acclimation abilities may go undetected with N-SSLC measurements. It should however be noted that duration of RLC light steps has to be as short as possible like in the present study (10 s) to modify the less as possible the acclimation status reached by phytoplankton communities immediately prior to the start of the curve measurement. The use of longer RLC light steps would reduce differences between the photosynthetic parameters extracted from RLC and N-SSLC because RLC ability to capture acclimation to recent light history is inversely proportional to light steps duration. Indeed, the longer the light steps, the more phytoplankton acclimate during the curve building and the more it is difficult to characterize differences in short-term acclimation status of algae exposed to contrasted environmental conditions just before the RLC measurement (Frankenbach and Serôdio 2017; Lefebvre et al. 2011; Perkins et al. 2006). 
By conducting laboratory experiments on natural communities and cultures of benthic microalgae, Serôdio et al. (2006) and Cruz and Serôdio (2008) found that besides providing information on the algal photosynthetic response to recent changes in ambient irradiance, RLC also inform on the long-term photoacclimation status, namely the status which was supposed to be exclusively measured with SSLC. Our results seem to be in accordance with these observations because at annual scale, the general trends of $\alpha_{-}$RLC and ETR $\mathrm{m}_{-}$RLC variations were very similar to $\alpha_{-} \mathrm{N}-\mathrm{SSLC}$ and $\mathrm{ETR}_{\mathrm{m} \_\mathrm{N}-\mathrm{SSLC}}$, while at this time scale the recent light history has a lower effect on photosynthetic parameters than at daily scale. However, the methodology employed still influenced the absolute values of photosynthetic parameters and higher values were obtained with N-SSLC.

Several explanations have been proposed to explain discrepancies between the photosynthetic parameters extracted from RLC and SSLC. Serôdio et al. (2006) and Cruz and Serôdio (2008) explained differences between $\mathrm{ETR}_{\mathrm{m} \_ \text {RLC }}$ and $\mathrm{ETR}_{\mathrm{m}}$ measured with SSLC $\left(\mathrm{ETR}_{\mathrm{m} \_\mathrm{SSLC}}\right)$ by the activation of the carbon metabolism during the final steps of SSLC or by its rapid de-activation during RLC measurement. According to Perkins et al. (2006), the inequality between $\mathrm{ETR}_{\mathrm{m} \_\mathrm{RLC}}$ and $\mathrm{ETR}_{\mathrm{m} \_\mathrm{SSLC}}$ results from the light dose effect experienced during the curve itself which primarily involves the rate of primary quinone acceptor $\mathrm{Q}_{\mathrm{A}}$ reoxydation and the induction of the non-photochemical quenching (NPQ). $\mathrm{Q}_{\mathrm{A}}$ reoxydation has the strongest impact particularly during RLC. The short light steps of RLC applied sequentially do not allow the complete reoxydation of $\mathrm{Q}_{\mathrm{A}}$ between each irradiance step which lead to the accumulation of reduced electron acceptors down to PSII. This has a higher impact on the last light steps and consequently results in lower values of $\mathrm{ETR}_{\mathrm{m} \_\mathrm{RLC}}$ in comparison to $\mathrm{ETR}_{\mathrm{m} \_\mathrm{SSLC}}$ (Lefebvre et al. 2011; Perkins et al. 2006). NPQ induced by light dose accumulation during the curve may also be involved but in a more complex way. It impacts the acquisition of $\mathrm{F}^{\prime}$ and $\mathrm{F}_{\mathrm{m}}$ ' used in the calculation of ETR and it was found that the level of NPQ induced by light dose accumulation increases proportionally to the duration of light steps (Perkins et al. 2006). Differences between $\alpha_{-}$RLC and $\alpha_{-}$SSLC have also been explained by the influence of NPQ (Cruz and Serôdio 2008; Lefebvre et al. 2011; Perkins et al. 2006; Serôdio et al. 2006). It has been shown that NPQ formed in response to an excess in environmental light conditions just before the RLC measurement, dissipates incompletely during the first light steps on which the estimation of $\alpha \_$RLC is based. As a consequence, lower values of $\alpha_{-}$RLC are obtained in comparison to $\alpha_{-}$SSLC because SSLC allow NPQ to completely relax during the first light steps (Cruz and Serôdio 2008; Lefebvre et al. 2011; Serôdio et al. 
2006). In our study, discrepancies between $\alpha_{-}$RLC and $\alpha_{-}$N-SSLC cannot be explained by the incomplete dissipation of NPQ during the first light steps because at the beginning of RLC and N-SSLC, the level of NPQ was always close to zero and NPQ processes only start to be activated during the curves building (by light dose accumulation). Nevertheless, at annual scale, NPQ induced by light dose accumulation during the curve may have played a role in the differences between the photosynthetic parameters ( $\alpha$ and ETR $\mathrm{m}_{\mathrm{m}}$ ) extracted from RLC and NSSLC because the maximum level of NPQ reached during the curves and the slope of the NPQ vs. E curve were higher under N-SSLC than RLC. The sequential application of the light steps during RLC in opposition to the light steps independency during N-SSLC have to be mentioned as factors contributing to gaps between RLC and N-SSLC photosynthetic parameters. Indeed, light history and accumulation during these light curves are not identical. This may induce different acclimation processes during the curve building and may impact differently the photosynthetic parameters extracted. For the same biofilm of benthic microalgae, Herlory et al. (2007) obtained different $\alpha$ and $\mathrm{ETR}_{\mathrm{m}}$ values after measurement of light response curves with exactly the same light steps duration (50 s) and intensities but applied sequentially vs. non-sequentially. This is because dynamics of the effective quantum yield of photosystem II and development of NPQ were different during both curve measurements. Also by measuring sequential vs. non-sequential light response curves on microphytobenthos, Frankenbach and Serôdio (2017) showed that photosynthetic parameters extracted from non sequential light response curves were less affected by light conditions to which algae were exposed 15 min before the curve measurement than photosynthetic parameters extracted from RLC. As highlighted by multiple linear regressions, temperature and phytoplankton communities composition have also played a role in deviations between RLC and N-SSLC photosynthetic parameters. This is likely because photoacclimation processes vary between phytoplankton species (e.g. Moore et al. 2006) and involve enzymes which are temperature-dependent (Davidson 1991). Under different temperatures and according to their composition, phytoplankton communities may thus set up different photoacclimation processes during RLC and N-SSLC measurements.

\section{Use of RLC to assess the photoacclimation status at steady-state}

One of the objectives of this study was to characterize at different time scales, the relationship between RLC and N-SSLC under a wide range of environmental conditions and 
phytoplankton community structures. The underlying goal was to evaluate the possibility to use RLC to predict the photosynthetic parameters at steady-state and thus to define the longterm phytoplankton photoacclimation status in the context of field studies. According to Serodio et al. (2006), the relationship between the photosynthetic parameters extracted from RLC and SSLC is strongly dependent on the level of ambient irradiance to which algae have been acclimated before the measurement of light response curves. As a result, the use of $\alpha_{-}$RLC to predict $\alpha \_$SSLC is only possible when algae have been exposed to low ambient irradiance while $\mathrm{ETR}_{\mathrm{m} \_\mathrm{RLC}}$ can provide a reasonable prediction of $\mathrm{ETR}_{\mathrm{m} \_\mathrm{SSLC}}$ only after acclimation to high irradiance. Due to this inverse possibility to predict $\alpha_{-} \mathrm{SSLC}$ and $\mathrm{ETR}_{\mathrm{m} \_\mathrm{SSLC}}$ from $\alpha_{\_} \mathrm{RLC}$ and $\mathrm{ETR}_{\mathrm{m} \_ \text {RLC }}, \mathrm{E}_{\mathrm{k} \_ \text {SSLC }}$ cannot be predicted using $\mathrm{E}_{\mathrm{k} \_ \text {RLC }}$ (Serôdio et al. 2006). About $\mathrm{E}_{\mathrm{k}}$, our results confirm the observations of Serôdio et al. (2006) because no significant linear relationship was found between $\mathrm{E}_{\mathrm{k} \_ \text {N-SSLC }}$ and $\mathrm{E}_{\mathrm{k} \_ \text {RLC }}$ at daily scale as well as at annual scale. Nevertheless, it should be noted that at annual scale even though the relationship between $\mathrm{E}_{\mathrm{k} \_\mathrm{N}-\mathrm{SSLC}}$ and $\mathrm{E}_{\mathrm{k} \_ \text {RLC }}$ is not significant, conclusions about the phytoplankton acclimation status remain the same. In the case of phytoplankton, it seems to be mainly the RLC susceptibility to measure rapid changes in $\alpha$ and ETR $_{m}$ which would have been passed unnoticed with N-SSLC measurements (and thus the time scale at which measurements are made) that influences the possibility to use RLC parameters to predict SSLC parameters rather than the level of ambient irradiance to which algae have been acclimated before the curve measurement. Indeed, at annual scale, even though ambient irradiance followed a seasonal cycle, there was not a seasonal signal in the difference between $\alpha_{-}$RLC and $\alpha_{-} \mathrm{N}$-SSLC and between $\mathrm{ETR}_{\mathrm{m} \_ \text {RLC }}$ and $\mathrm{ETR}_{\mathrm{m} \_\mathrm{N}-\mathrm{SSLC}}$ and the highest differences between $\mathrm{ETR}_{\mathrm{m} \_\mathrm{RLC}}$ and $\mathrm{ETR}_{\mathrm{m} \_\mathrm{N}-\mathrm{SSLC}}$ were observed in spring and summer i.e. during periods where algae were exposed to the highest ambient irradiances. Additionally, at daily scale, it was not systematically during the periods with the highest irradiance that the relationship between $\mathrm{ETR}_{\mathrm{m} \_ \text {RLC }}$ and $\mathrm{ETR}_{\mathrm{m} \_\mathrm{N}-\mathrm{SSLC}}$ was the best and inversely for $\alpha_{\_}$RLC and $\alpha_{\_}$N-SSLC. By contrast, relationships between the photosynthetic parameters extracted from RLC and N-SSLC were better at annual scale than at daily scale. As a consequence, because RLC measurements better capture the short-term changes in photosynthetic activity than N-SSLC do, at daily scale, relationships between photosynthetic parameters resulting from RLC and N-SSLC may not be linear. The use of RLC to predict NSSLC photosynthetic parameters is thus compromised. However, this seems possible at annual scale because at this time scale, recent changes in environmental conditions have a lower influence on photosynthesis and stronger relationships have been observed between 
$\mathrm{ETR}_{\mathrm{m} \_ \text {RLC }}$ and ETR $\mathrm{m}_{-} \mathrm{N}-\mathrm{SSLC}$ and between $\alpha_{-} \mathrm{RLC}$ and $\alpha_{-} \mathrm{N}-\mathrm{SSLC}$ regardless of the seasonal variations in physico-chemical parameters and phytoplankton structure.

\section{Conclusions}

The results of this study highlight the usefulness of RLC to accurately characterize short-term and long-term in situ variations in phytoplankton photosynthetic performances and acclimation status. At daily scale, RLC measurements are strongly sensitive to recent phytoplankton light history and short-term acclimation status which allows for detecting rapid changes in photosynthetic activity that would have been overlooked with N-SSLC measurements. This ability is advantageous to study phytoplankton photosynthesis in environments with rapidly fluctuating conditions such as coastal systems with high water mixing rates or estuaries. Besides these short-term changes, RLC can also be used to follow seasonal fluctuations in phytoplankton photosynthesis as they inform on the long-term photoacclimation status in a very similar way to N-SSLC. Absolute values of photosynthetic parameters and ETR extracted from RLC are impacted by the short duration of light steps which leads to lower values in comparison to N-SSLC. However, at annual scale, information about the steady-state photoacclimation status can be obtained from RLC measurements using the strong linear relationships between RLC and N-SSLC measurements to make a correction. In their application at this time scale, RLC have the advantage over N-SSLC of drastically shortening the time required for measurement and they allow replication.

\section{Acknowledgments}

We thank Xavier Mériaux for technical assistance in chl a-specific absorption coefficients analyses. We thank anonymous reviewers for their critical comments that improved the manuscript.

\section{Compliance with ethical standards}

Funding This study was part of E.H.'s PhD thesis defended on September $25^{\text {th }} 2012$ and financially supported by a grant from the French "Ministère de l'Enseignement Supérieur et 
de la Recherche” and the DYMAPHY INTERREG IVA “2 Mers Seas Zeeën” project cofunded by the European Union (ERDF funds).

Conflict of interest The authors declare that they have no conflict of interest.

Human and animal right statement This article does not contain any studies with animals performed by any of the authors.

\section{References}

Aminot A, Kérouel R (2004) Hydrologie des écosystèmes marins. Paramètres et analyses. Editions de l'Ifremer, Brest. pp. 335,

Aminot A, Kérouel R (2007) Dosage automatique des nutriments dans les eaux marines vol 1. Editions de l'Ifremer. pp. 188,

Baly ECC (1935) The kinetics of photosynthesis Proceeding of the royal society B Biological Sciences 177:218-239

Brunet C, Johnsen G, Lavaud J, Roy S (2011) Pigments and photoacclimation processes. In: Roy S. et al. (ed) Phytoplankton pigments. pp 445-471

Clarke KR, Warwick RM (1994) Change in marine communities: an approach to statistical analysis and interpretation. Natural Environment Research Council, UK: 144 pp,

Cruz S, Serôdio J (2008) Relationship of rapid light curves of variable fluorescence to photoacclimation and non-photochemical quenching in a benthic diatom Aquatic Botany 88:256-264

Davidson IR (1991) Environmental effects on algal photosynthesis: temperature Journal of phycology 27:2-8

Frankenbach S, Serôdio J (2017) One pulse, one light curve: Fast characterization of the light response of microphytobenthos biofilms using chlorophyll fluorescence Limnology and Oceanography: Methods 15:554-566

Gaarder T, Gran HH (1927) Production of plankton in the Oslo Fjord Rapports et ProcèsVerbaux des Réunions Conseil Permanent International pour l'Exploration de la Mer 42:1-48

Geider RJ, MacIntyre HL, Kana TM (1998) A dynamic regulatory model of phytoplanktonic acclimation to light, nutrients, and temperature Limnology and Oceanography 43:679694

Genty B, Briantais JM, Baker NR (1989) The relationship between the quantum yield of photosynthetic electron transport and quenching of chlorophyll fluorescence Biochimica et Biophysica Acta 990:87-92

Gilbert M, Domin A, Becker A, Wilhelm C (2000) Estimation of primary productivity by chlorophyll $a$ in vivo fluorescence in freshwater phytoplankton Photosynthetica 38:111-126

Hama T, Miyazaki T, Ogawa Y, Iwakuma T, Takahashi M, Otsuki A, Ichimura S (1983) Measurement of photosynthetic production of a marine phytoplankton population using a stable ${ }^{13} \mathrm{C}$ isotope Marine Biology 73:31-36

Henley WJ (1993) Measurement and interpretation of photosynthetic light-response curves in algae in the context of photoinhibition and diel changes Journal of Phycology 29:729738 
Herlory O, Richard P, Blanchard GF (2007) Methodology of light response curves: application of chlorophyll fluorescence to microphytobenthic biofilms Marine Biology 153:91-101

Houliez E, Lizon F, Artigas LF, Lefebvre S, Schmitt FG (2013a) Spatio-temporal variability of phytoplankton photosynthetic activity in a temperate macrotidal ecosystem: a novel use of Pulse Amplitude Modulated (PAM) fluorometry Estuarine, Coastal and Shelf Science 129:37-48

Houliez E, Lizon F, Lefebvre S, Artigas LF, Schmitt FG (2013b) Short-term variability and control of phytoplankton photosynthetic activity in a macrotidal ecosystem (the Strait of Dover, eastern English Channel) Marine Biology 160:1661-1679

Houliez E, Lizon F, Thyssen M, Artigas LF, Schmitt FG (2012) Spectral fluorometric characterization of Haptophyte dynamics using the FluoroProbe: an application in the eastern English Channel for monitoring Phaeocystis globosa Journal of Plankton Research 34:136-151

Kolber ZS, Prasil O, Falkowski PG (1998) Measurements of variable chlorophyll fluorescence using fast repetition rate techniques: Defining methodology and experimental protocols Biochimica et Biophysica Acta - Bioenergetics 1367:88-106

Kolbowski J, Schreiber U (1995) Computer-controlled phytoplankton analyser based on a 4wavelengths PAM chlorophyll fluorometer. In: Mathis P (ed) Photosynthesis: from Light to Biosphere (V). Kluwer Academic Publishers, Dordrecht, The Netherlands, pp 825-828

Kromkamp J, Forster R (2003) The use of variable fluorescence measurements in aquatic ecosystems: differences between multiple and single turnover measuring protocols and suggested terminology European Journal of Phycology 38:103-112

Lawrenz E et al. (2013) Predicting the Electron Requirement for Carbon Fixation in Seas and Oceans PLoS ONE 8:e58137

Lefebvre S, Mouget JL, Lavaud J (2011) Duration of rapid light curves for determining the photosynthetic activity of microphytobenthos biofilm in situ Aquatic Botany 95:1-8

Lefebvre S, Mouget JL, Loret P, Rosa P, Tremblin G (2007) Comparison between fluorimetry and oximetry techniques to measure photosynthesis in the diatom Skeletonema costatum cultivated under simulated seasonal conditions Journal of Photochemistry and Photobiology B: Biology 86:131-139

Lorenzen CJ (1966) A method for continuous measurement of in vivo chlorophyll concentration Deep-Sea Research (Part I, Oceanographic Research Papers) 13:223247

MacIntyre HL, Kana TM (2002) Photoacclimatation of photosynthesis irradiance response curves and photosynthetic pigments in microalgae and cyanobacteria Journal of Phycology 38:17-38

MacIntyre HL, Kana TM, Geider RJ (2000) The effect of water motion on short-term rates of photosynthesis by marine phytoplankton Trends in plant science 5:12-17

Mitchell B (1990) Algorithms for determining the absorption coefficient of aquatic particulates using the quantitative filter technique (QFT) Ocean Optics X:137-148

Mitchell BG, Kahru M, Wieland J, Stramska M (2003) Determination of spectral absorption coefficients of particles, dissolved material and phytoplankton for discrete water samples. In: Mueller JL, Fargion GS, McClain CR (eds) Ocean Optics Protocols for Satellite Ocean Color Sensor Validation. Revision 4-Volume IV, NASA Technical Memorandum 2003-211621, pp 39-64

Montford K (1969) Measuring dissolved oxygen as an indicator of primary productivity Chesapeake Science 10:327-330 
Moore CM et al. (2006) Phytoplankton photoacclimation and photoadaptation in response to environmental gradients in shelf sea Limnology \& Oceanography 51:936-949

Nelder JA, Mead R (1965) A simplex method for function minimization The Computer Journal 7:308-313

Perkins RG et al. (2010) The Application of Variable Chlorophyll Fluorescence to Microphytobenthic Biofilms. In: Suggett DJ (ed) Chlorophyll a Fluorescence in Aquatic Sciences : Methods and Applications. Springer Dordrecht Heidelberg, London, New York, pp 237-275.

Perkins RG, Mouget JL, Lefebvre S, Lavaud J (2006) Light response curve methodology and possible implications in the application of chlorophyll fluorescence to benthic diatoms Marine Biology 149:703-712

R Core Team (2016) R: a language and environment for statistical computing. Vienna, Austria

Ratkowski DA (1983) Non linear regression modeling. A unified practical approach. Marcel Dekker, New York, p 276.,

Sakshaug E et al. (1997) Parameters of photosynthesis: Definitions, theory and interpretation of results Journal of Plankton Research 19:1637-1670

Scherrer B (2007) Biostatistique, Volume 1, 2e édition. Gaëtan Morin éditeur. 816 pp.,

Schreiber U (1998) Chlorophyll fluorescence: New instruments for special applications. In: G. G (ed) Photosynthesis: Mechanisms and Effects, vol 5. pp 4253-4258

Schreiber U (2004) Pulse-Amplitude-Modulation (PAM) fluorometry and saturation pulse method : an overview. In: Papageorgiou G, Govindjee (eds) Chlorophyll Fluorescence : a Signature of Photosynthesis, vol 19. Kluwer Academic Publishers, Dordrecht, The Netherlands, pp 279-319

Schreiber U, Gademann R, Ralph PJ, Larkum AWD (1997) Assessment of photosynthetic performance of Prochloron in Lissoclinum patella in hospite by chlorophyll fluorescence measurements Plant Cell Physiology 38:945-951

Serôdio J, Cruz S, Vieira S, Brotas V (2005a) Non-photochemical quenching of chlorophyll fluorescence and operation of the xanthophyll cycle in estuarine microphytobenthos Journal of Experimental Marine Biology and Ecology 326:157-169

Serôdio J, Lavaud J (2011) A model for describing the light response of the nonphotochemical quenching of chlorophyll fluorescence Photosynthesis Research 108:61-76

Serôdio J, Vieira S, Cruz S (2008) Photosynthetic activity, photoprotection and photoinhibition in intertidal microphytobenthos as studied in situ using variable chlorophyll fluorescence Continental Shelf Research 28:1363-1375

Serôdio J, Vieira S, Cruz S, Barroso F (2005b) Short-term variability in the photosynthetic activity of microphytobenthos as detected by measuring rapid light curves using variable fluorescence Marine Biology 146:903-914

Serôdio J, Vieira S, Cruz S, Coelho H (2006) Rapid light-response curves of chlorophyll fluorescence in microalgae: Relationship to steady-state light curves and nonphotochemical quenching in benthic diatom-dominated assemblages Photosynthesis Research 90:29-43

Steemann Nielsen E (1952) The Use of Radio-active Carbon $\left(\mathrm{C}^{14}\right)$ for Measuring Organic Production in the Sea ICES Journal of Marine Science 18:117-140 doi:10.1093/icesjms/18.2.117

Suggett DJ, Moore CM, Geider JR (2010) Estimating Aquatic Productivity from Active Fluorescence Measurements. In: Suggett DJ (ed) Chlorophyll $a$ Fluorescence in Aquatic Sciences : Methods and Applications. Springer Dordrecht Heidelberg, London, New York, pp 103-127. 
van Kooten O, Snel JFH (1990) The use of chlorophyll fluorescence nomenclature in plant stress physiology Photosynthesis Research 25:147-150

Venables WN, Ripley BD (2002) Modern applied statistics with S. Fourth Edition. Springer, New York. 498 p.

Webb WL, Newton M, Starr D (1974) Carbon dioxide exchange of Alnus rubra : a mathematical model Ecologia 17:281-291

White AJ, Critchley C (1999) Rapid light curves : a new fluorescence method to assess the state of the photosynthetic apparatus Photosynthesis Research 59:63-72 